\title{
Effects of vegetation structure on biomass accumulation in a Balanced Optimality Structure Vegetation Model (BOSVM v1.0)
}

\author{
Z. Yin ${ }^{1}$, S. C. Dekker ${ }^{2}$, B. J. J. M. van den Hurk ${ }^{1,3}$, and H. A. Dijkstra ${ }^{1}$ \\ ${ }^{1}$ Institute for Marine and Atmospheric research Utrecht, Utrecht University, Utrecht, the Netherlands \\ ${ }^{2}$ Copernicus Institute of Sustainable Development, Utrecht University, Utrecht, the Netherlands \\ ${ }^{3}$ Royal Netherlands Meteorological Institute, De Bilt, the Netherlands
}

Correspondence to: Z. Yin (z.yin@uu.nl)

Received: 18 July 2013 - Published in Geosci. Model Dev. Discuss.: 9 September 2013

Revised: 3 February 2014 - Accepted: 4 March 2014 - Published: 12 May 2014

\begin{abstract}
A myriad of interactions exist between vegetation and local climate for arid and semi-arid regions. Vegetation function, structure and individual behavior have large impacts on carbon-water-energy balances, which consequently influence local climate variability that, in turn, feeds back to the vegetation. In this study, a conceptual vegetation structure scheme is formulated and tested in the new Balanced Optimality Structure Vegetation Model (BOSVM) to explore the importance of vegetation structure and vegetation adaptation to water stress on equilibrium biomass states. Surface energy, water and carbon fluxes are simulated for a range of vegetation structures across a precipitation gradient in West Africa and optimal vegetation structures that maximize biomass for each precipitation regime are determined. Two different strategies of vegetation adaptation to water stress are included. Under dry conditions vegetation tries to maximize the water use efficiency and leaf area index as it tries to maximize carbon gain. However, a negative feedback mechanism in the vegetation-soil water system is found as the vegetation also tries to minimize its cover to optimize the surrounding bare ground area from which water can be extracted, thereby forming patches of vertical vegetation. Under larger precipitation, a positive feedback mechanism is found in which vegetation tries to maximize its cover as it then can reduce water loss from bare soil while having maximum carbon gain due to a large leaf area index. The competition between vegetation and bare soil determines a transition between a "survival" state to a "growing" state.
\end{abstract}

\section{Introduction}

Vegetation has a significant impact on the regional climate at different spatial and temporal scales through interactions with the atmosphere, the hydrological cycle and the surface energy balance (Bonan, 2008; Dekker et al., 2010). Positive and negative vegetation-climate feedbacks can affect the local climate variability, particularly in arid and semiarid regions, owing to the complex vegetation-atmosphere interactions and strong gradients in climate regimes (Entekhabi et al., 1992; Koster et al., 2004; Dekker et al., 2007; Seneviratne et al., 2010). Vegetation feedbacks mitigate surface warming by transpiration, but simultaneously can increase the surface energy absorption by reduction of the surface albedo, affecting the resilience to drought (Bonan, 2008; Teuling et al., 2010).

For arid and semi-arid areas, the strong gradients and spatial variability of vegetation cover (Sankaran et al., 2005; Dijkstra, 2011) and the gross complexity of interactions between vegetation, precipitation (Higgins et al., 2010; Baudena et al., 2010) and bare soil (Zeng et al., 1999; Rietkerk et al., 2002; Koster et al., 2004; Seneviratne et al., 2010) introduce a large range of equilibrium states. An adequate representation of the regimes of interaction between vegetation and climate is necessary to understand the role of vegetation in the climate system, including the ecosystem response to climate change. For this, an enhanced knowledge of soil moisture-vegetation-atmosphere interactions and feedbacks at multiple spatial and temporal scales is needed (Kéfi et al., 2007; Seneviratne et al., 2010; Dijkstra, 2011; Rietkerk et al., 2011). 
In arid and semi-arid areas, water availability is a primary factor for photosynthesis and vegetation development (Seneviratne et al., 2010). In a model experiment, Koster et al. (2004) revealed that soil moisture and precipitation are strongly coupled in water transition zones, including the Western Africa monsoon area. This strong interaction points at a potentially strong role of vegetation-climate interactions in this region. Observations show a good correspondence between maximum vegetation cover and annual mean precipitation (Sankaran et al., 2005; Hirota et al., 2011; Guan et al., 2012). However, for a given precipitation amount the observed cover fraction of woody vegetation varies significantly. One factor that may play a role here is the vegetation response to fire (Sankaran et al., 2005; Higgins et al., 2010; Hirota et al., 2011; Staver et al., 2011), which will lead to a fast replacement of woody vegetation by grass. This can explain the strong variability of woody vegetation cover in so-called "alternative stable states" (Hirota et al., 2011). Baudena et al. (2010) showed how the co-existent regimes of tree and grass species depend on the chosen parameterization options in their conceptual model, pointing at the need for a detailed understanding of the underlying biophysical processes.

Recently, many studies focus on how precipitation influences vegetation patterns through processes of water redistribution, such as positive feedbacks due to infiltration (Rietkerk et al., 2002), shading (Baudena and Provenzale, 2008) and topography (Klausmeier, 1999). In these studies transpiration, which is the crucial process in water, carbon and energy balances, is not explicitly modeled. In these conceptual models, the transpiration rate simply has a positive relation with biomass density, vegetation fraction or soil water stress. However, the ability of these conceptual models to describe vegetation dynamics and feedbacks to specific climate is generally limited by their degree to which mechanistic processes are included and energy or mass balance closure is satisfied. In addition, different strategies of vegetation response to drought (Calvet, 2000; Calvet et al., 2004) will also influence vegetation fraction and biomass significantly. On the other hand, these conceptual models are tested under simulated precipitation gradient. In fact, across the precipitation gradient, other climate variables (radiation, air humidity, wind speed, soil, etc.) also vary and influence vegetation processes (Dardel et al., 2014).

In the interaction between vegetation and the coupled carbon-water-energy balances, spatial structure of vegetation plays an important role in transpiration on multiple timescales (e.g., Konings et al., 2011). Within a given set of climate conditions, a large variation of water uptake ability and $\mathrm{CO}_{2}$ assimilation rate exists, controlled by vegetation structure characteristics such as root biomass, leaf area index (LAI) and leaf cover $\left(f_{\mathrm{c}}\right)$. LAI affects the potential transpiration rate of plants and changes the surface albedo, which controls the solar energy absorption of the land surface. $f_{\mathrm{c}}$ plays a key role in the vegetation-bare soil competition for water and energy. In water-limited regimes, bare ground evaporation will reduce the available water needed for photosynthesis, directly affecting biomass accumulation. In addition, the shoot-root distribution of vegetation determines the balance between water uptake and carbon gain.

Both LAI and $f_{\mathrm{c}}$ increase as biomass is accumulated. However, for a given leaf biomass, different spatial structures of vegetation can be generated. High $\mathrm{LAI} / f_{\mathrm{c}}$ values imply an ecosystem developing a vertical structure (e.g., individual trees or patches of dense grasses), while low $\mathrm{LAI} / f_{\mathrm{c}}$ is representative for horizontally oriented vegetation structures (e.g., grassland or rainforest).

Simultaneously, different strategies exist on regulating stomata response to water stress. Calvet (2000) and Calvet et al. (2004) identified two distinct strategies (drought avoiding and drought tolerant), which affect the response of vegetation to shorter or longer dry periods. Drought tolerant ("offensive") species tend to maximize water use in dry conditions, rapidly making benefit of precipitation events in a dry climate. Drought avoiding ("defensive") strategy leads to a more conservative response to moisture anomalies, aiming at preserving water for times of scarcity.

In this study, our primary objective is to formulate a new vegetation model that considers the effect of spatial structure and adaption to local climate via interactions between the carbon-water-energy cycles. Meanwhile, the new model must be easily linked to existing climate model for further vegetation-land-atmosphere interaction studies.

To approach the objective, a new coupled model coupling carbon-water-energy balances (Balanced Optimality Structure Vegetation Model BOSVM) is developed from existing model components. Vegetation structure parameterization follows LPJ (Sitch et al., 2003) and TRIFFID (Cox, 2001). Photosynthesis and canopy conductance simulation are based on CHTESSEL (Boussetta et al., 2013) and Calvet (2000); Calvet et al. (2004). Energy and water balances are calculated as formulated in TESSEL (van den Hurk et al., 2000; Balsamo et al., 2009). The Monin-Obukhov similarity theory (Oleson et al., 2004; ECMWF, 2008) is applied for estimation of aerodynamic exchange. We make use of existing concepts of current ecological and hydrometeorological models, but configured with sufficient flexibility to explore a range of relevant features related to the vegetation structure, competition with bare ground evaporation, and light absorption. The BOSVM model includes the main physical and biological land surface processes coupling the cycles of carbon, water and energy. Although soil types do play an important role in vegetation response to climate (Dardel et al., 2014), its distribution is independent to the precipitation gradient. Thus, we only apply medium soil texture (Balsamo et al., 2009) in this study and ignore effects of soil types on biomass dynamics. The definition of the vegetation structure in the BOSVM model is conceptualized in order to represent spatial structures of vegetation in different plant function types (PFTs). Competition between bare soil and vegetation is included by using a tiling method (van den Hurk 
et al., 2000). In a next study, we will try to enhance our knowledge of the role vegetation plays in land-atmosphere interactions. The BOSVM model developed in this study can be easily combined with existing climate models for future land-atmosphere interaction studies.

To understand how vegetation adapts to its local climate by changing its spatial structure, an optimization approach is applied by assuming that vegetation tries to maximize its total biomass (Schymanski et al., 2010). Over the past decades, numerous objective functions were proposed to explain the universal principle of vegetation adjustment to climate, such as maximizing water use efficiency (Schymanski et al., 2008), maximizing net carbon profit (Schymanski et al., 2007; Dekker et al., 2010) or minimizing soil water stress (Rodriguez-Iturbe et al., 1999). However, Schymanski et al. (2010) found that maximizing total biomass is in principle equal to maximum entropy production, which is a universal objective function for ecosystem dynamics in the carbonwater-energy cycles (Dewar, 2003; Kleidon, 2004; Kleidon and Schymanski, 2008). Through the maximization process, we will show how optimal vegetation structure (maximizing total biomass) shifts with the change of climate regime by adjusting carbon allocation and strategies to drought. By understanding the mechanism that leads to a shift of the optimal structure, we can enhance the predictability of phenology change with climate.

\section{Methodology: BOSVM description and experimental design}

The primary aspect of the BOSVM model is the combination of water, carbon, and energy balances. During the closing of these three balances, surface conductance $\left(g_{\mathrm{s}}\right)$ plays a crucial role, which is influenced by numerous climate variables. Instead of using an empirical stress formulation of the Jarvis approach (Jarvis, 1976), we first simulate vegetation photosynthesis activity, which highly depends on both vegetation behavior and climate condition. From photosynthesis simulation, we retrieve surface conductance and use it in the Monin-Obukhov similarity theory to estimate aerodynamic conductance $\left(g_{\mathrm{a}}\right)$. After $g_{\mathrm{s}}$ and $g_{\mathrm{a}}$ are known, we can estimate sensible and latent heat flux by closing the surface energy balance. States of surface temperature, soil water and total biomass will be updated. Based on specific vegetation structure parameters ( $\alpha$ and $D$ ) and updated biomass, we can calculate LAI, vegetation cover and root density in the next time step.

Section 2.1 introduces the fundamental equations of the energy, water and carbon balances. Section 2.2 illustrates the definitions of vegetation structures and formulation of structure variables (LAI, $f_{\mathrm{c}}$ and root density). In Sects. 2.3, 2.4 and 2.5, detailed parameterization of terms in carbon, energy and water balance equations (in Sect. 2.1) are displayed, respectively. Section 2.6 introduces two vegetation strategies to water stress found by Calvet (2000) and Calvet et al. (2004). In addition, we illustrate corresponding intrinsic water use efficiency as a function of extractable soil water content. In Sect. 2.7, we discuss how vegetation structure parameters affect biomass via LAI, $f_{\mathrm{c}}$ and root density. Sections 2.8 and 2.9 show the details of simulation process and information of study area, respectively.

\subsection{Model concepts}

The BOSVM model is designed to describe the coupled dynamics of the budgets of surface energy, water and carbon. Each budget is governed by a balance equation given by

$$
\begin{aligned}
R_{\mathrm{n}} & =H+l E+G \\
\frac{\mathrm{d} W}{\mathrm{~d} t} & =(P-\text { Leak }-E) \mathrm{CA}_{\mathrm{ref}} \\
\frac{\mathrm{d} C_{\mathrm{veg}}}{\mathrm{d} t} & =\mathrm{NPP} \cdot \mathrm{CA}-\mathrm{LIT},
\end{aligned}
$$

where the budgets for water and energy are expressed as mass or energy per unit crown area. $R_{\mathrm{n}}\left[\mathrm{W} \mathrm{m}^{-2}\right]$ is net radiation; $H\left[\mathrm{~W} \mathrm{~m}^{-2}\right]$ is sensible heat flux; $l E\left[\mathrm{~W} \mathrm{~m}^{-2}\right]$ is latent heat flux and $G\left[\mathrm{~W} \mathrm{~m}^{-2}\right]$ is soil heat flux; $W\left[\mathrm{~kg} \mathrm{H}_{2} \mathrm{O}\right]$ is total water stored in the soil; $P\left[\mathrm{~kg} \mathrm{H}_{2} \mathrm{O} \mathrm{m}^{-2} \mathrm{~s}^{-1}\right]$ is the precipitation rate; Leak $\left[\mathrm{kg} \mathrm{H}_{2} \mathrm{O} \mathrm{m}^{-2} \mathrm{~s}^{-1}\right]$ is water leakage through bottom drainage; $E\left[\mathrm{~kg} \mathrm{H}_{2} \mathrm{O} \mathrm{m}^{-2} \mathrm{~s}^{-1}\right]$ is the evapotranspiration rate; $\mathrm{CA}_{\text {ref }}\left[\mathrm{m}^{2}\right]$ is the reference crown area, identical to the maximum size of an individual plant; $t[\mathrm{~s}]$ is the time step of the simulation; $C_{\mathrm{veg}}[\mathrm{kg} \mathrm{C}]$ is the total amount of biomass; NPP $\left[\mathrm{kg} \mathrm{C} \mathrm{m}^{-2} \mathrm{~s}^{-1}\right]$ is the net primary production; CA $\left[\mathrm{m}^{2}\right]$ is the crown area of vegetation; and LIT $\left[\mathrm{kg} \mathrm{Cs}^{-1}\right]$ is the generation of litter of vegetation.

\subsection{Carbon allocation and canopy structure}

The vegetation carbon biomass pool is distributed over aboveground and belowground components. In the BOSVM model, vegetation is separated into two classes: grass, for which the aboveground carbon pool consists of leaf biomass only, and woody plants, for which the aboveground biomass is composed of leaf biomass and stem biomass to support a high LAI (see top left panel of Fig. 1). The biomass composition function is therefore

$C_{\text {veg }}=C_{\text {leaf }}+C_{\text {root }}+C_{\text {stem }}$,

where $C_{\text {leaf }}[\mathrm{kgC}]$ is leaf biomass; $C_{\text {root }}[\mathrm{kgC}]$ is root biomass; $C_{\text {stem }}[\mathrm{kg} \mathrm{C}]$ is stem biomass (zero for grass, see Fig. 1).

The shoot-total biomass ratio $\alpha[-]$, defined by

$\alpha=\frac{C_{\text {leaf }}+C_{\text {stem }}}{C_{\text {veg }}}$,

where $\alpha$ is our first control parameter. A high value of $\alpha$ implies more biomass to be allocated to leaves, enhancing 

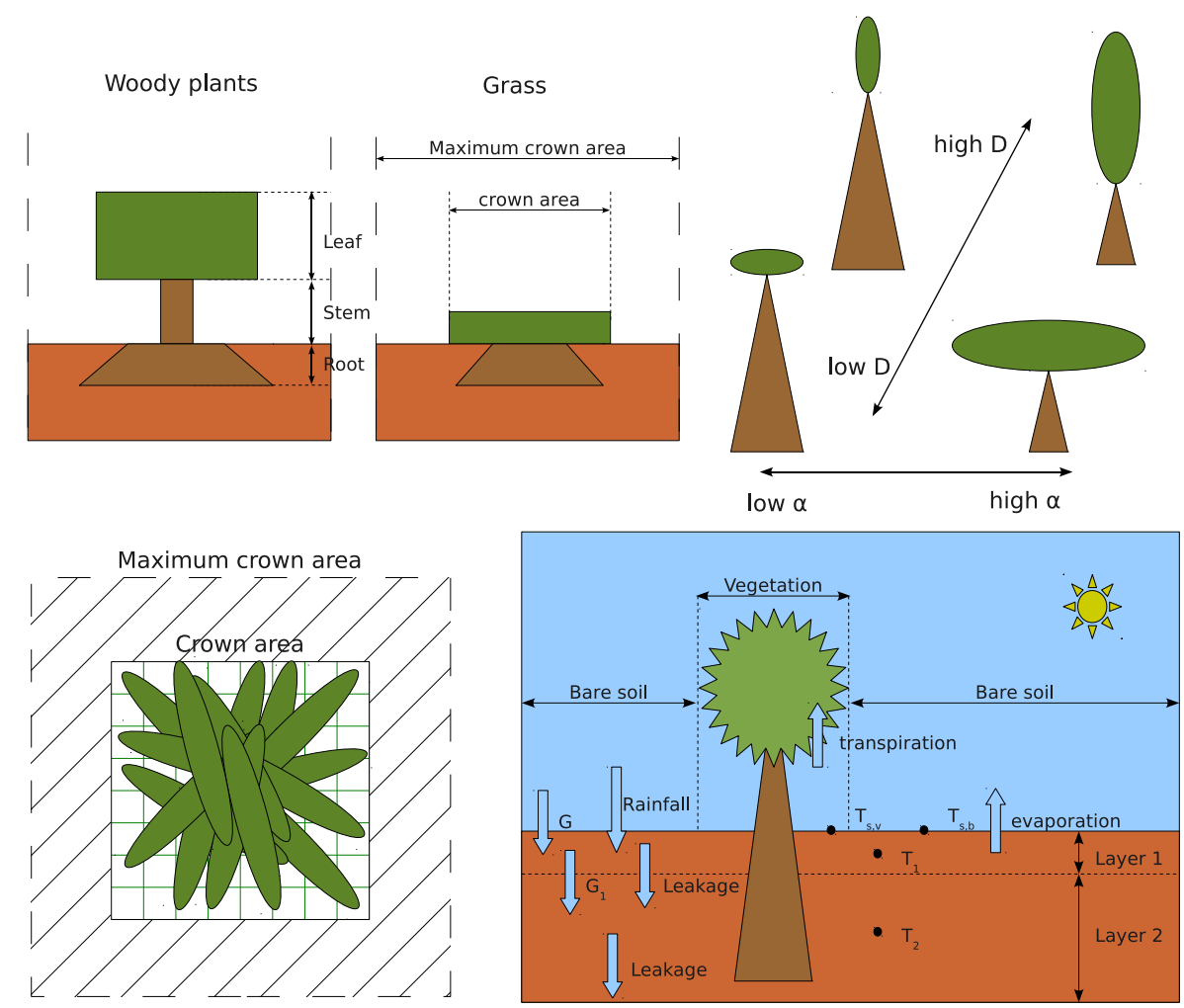

Fig. 1. Conceptual plot of vegetation structures and carbon-water-energy coupled model. Top left panel shows the composition of biomass for grass and woody plants (Eq. 4). Plant biomass is divided into aboveground (leaves and stems) and belowground (roots) biomass. The top right panel illustrates the control of the vegetation structure by the parameters $\alpha$ (fraction of aboveground biomass over total biomass, Eq. 5) and $D$ (canopy shape parameter, Eq. 8). A high value for $D$ represents a vertically oriented canopy. In the bottom left panel, the largest rectangle is the referenced crown area $\mathrm{CA}_{\text {ref }}$, while the smaller rectangle denotes the real crown area CA. Within the $\mathrm{CA}$, a fraction is covered by leaves, which depends on LAI (Eq. 9). The bottom right panel shows the tiling method (Eq. 13), the two-layer soil scheme (Eqs. 21 and 22) and the representation of water balances and soil heat fluxes.

the potential carbon assimilation rate, while a low $\alpha$ implies higher water uptake abilities due to higher root density (see top right panel of Fig. 1). Observed values of $\alpha$ range between 0 and 0.5 (Sitch et al., 2003).

For the allocation of stem biomass in woody vegetation, we use the expression from the TRIFFID model (Cox, 2001), reading

$$
\frac{C_{\text {stem }}}{\mathrm{CA}}=a_{l} \cdot \mathrm{LAI}^{5 / 3},
$$

where $a_{l}$ is a PFT-dependent parameter (see Table 1 for an overview of parameters used).

We calculate LAI following the global dynamic vegetation model LPJ (Sitch et al., 2003) using a predefined value of the specific leaf area (SLA), ignoring possible variation with leaf age or nitrogen content.

$\mathrm{LAI}=\frac{C_{\text {leaf }} \cdot \mathrm{SLA}}{\mathrm{CA}}$,

where SLA $\left[\mathrm{m}^{2} \mathrm{~kg} \mathrm{C}^{-1}\right]$ is a constant (Table 3 ). For a given value of $C_{\text {leaf }}$, CA is inversely proportional to LAI.
The second control parameter, representing the trade-off between crown area (CA) and leaf area index (LAI), is the ratio of relative CA to relative LAI (Eq. 8). The control parameter $D$ governs this ratio, using a scaling value $\mathrm{LAI}_{\text {ref }}$ as a constant (Table 3).

$$
D=\frac{\mathrm{LAI}}{\mathrm{LAI}_{\mathrm{ref}}} / \frac{\mathrm{CA}}{\mathrm{CA}_{\mathrm{ref}}}
$$

A high value of $D$ implies a vegetation canopy that has a vertical orientation, while a low $D$ means a horizontal structure (top right panel of Fig. 1). For a realistic description of real canopies, $D$ is varied in the range between 0.1 and 5 .

Vegetation fraction $f_{\mathrm{c}}$ is the ratio of projected leaf area to the reference crown area (bottom left panel of Fig. 1), which can be calculated by

$f_{\mathrm{c}}=f_{\mathrm{s}}\left(1-e^{-k \cdot \mathrm{LAI}}\right)$,

where $f_{\mathrm{s}}=\mathrm{CA} / \mathrm{CA}_{\text {ref }}[-]$ is the relative crown area; $k[-]$ is a constant extinction factor. 
Table 1. Parameterization of vegetation with two strategies.

\begin{tabular}{|c|c|c|c|c|c|c|}
\hline \multirow{3}{*}{ Parameters } & \multirow{3}{*}{ Unit } & \multicolumn{4}{|c|}{ Vegetation Type } & \multirow{3}{*}{ Reference } \\
\hline & & \multicolumn{2}{|c|}{ Grass } & \multicolumn{2}{|c|}{ Woody } & \\
\hline & & Defensive & Offensive & Defensive & Offensive & \\
\hline$A_{\max }\left(25^{\circ} \mathrm{C}\right)$ & $\mathrm{mgCm}^{-2} \mathrm{~s}^{-1}$ & 0.464 & 0.464 & 0.49 & 0.49 & Boussetta et al. (2013) \\
\hline$a_{1}$ & $\mathrm{kgC} \mathrm{m}^{-2}$ & - & - & 0.65 & 0.65 & $\operatorname{Cox}(2001)$ \\
\hline$D_{\max }$ & $\mathrm{g} \mathrm{kg}^{-1}$ & - & - & 100 & 100 & Calvet et al. (2004) \\
\hline$D_{\max }^{N}$ & $\mathrm{~g} \mathrm{~kg}^{-1}$ & 55 & - & - & - & Calvet (2000) \\
\hline$D_{\max }^{X}$ & $\mathrm{~g} \mathrm{~kg}^{-1}$ & - & 300 & - & - & Calvet (2000) \\
\hline$f_{0}^{*}$ & - & - & - & 0.606 & 0.46 & $\begin{array}{l}\text { Calvet (2000); } \\
\text { Calvet et al. (2004) }\end{array}$ \\
\hline$f_{0}$ & - & 0.6 & 0.6 & - & - & Boussetta et al. (2013) \\
\hline$f_{\mathrm{wc}}$ & $\mathrm{m}^{2} \mathrm{~m}^{-2}$ & 0.5 & 0.5 & 0.1 & 0.6 & $\begin{array}{l}\text { Calvet (2000); } \\
\text { Calvet et al. (2004) }\end{array}$ \\
\hline$g_{\mathrm{m}}^{*}\left(25^{\circ} \mathrm{C}\right)$ & $\mathrm{mms}^{-1}$ & 2.38 & 2.38 & 1.6 & 4.4 & $\begin{array}{l}\text { Calvet (2000); } \\
\text { Calvet et al. (2004) }\end{array}$ \\
\hline$\Gamma\left(25^{\circ} \mathrm{C}\right)$ & ppm & 2.8 & 2.8 & 42 & 42 & Boussetta et al. (2013) \\
\hline$\epsilon_{0}^{*}$ & $10^{-3} \mathrm{mg} \mathrm{C} \mathrm{J}^{-1}$ & 3.82 & 3.82 & 4.64 & 4.64 & Boussetta et al. (2013) \\
\hline$T_{1, \mathrm{Am}}$ & ${ }^{\circ} \mathrm{C}$ & 13 & 13 & 8 & 8 & Calvet (2000) \\
\hline$T_{2, \mathrm{Am}}$ & ${ }^{\circ} \mathrm{C}$ & 38 & 38 & 38 & 38 & Calvet (2000) \\
\hline$T_{1, \mathrm{~g}}$ & ${ }^{\circ} \mathrm{C}$ & 13 & 13 & 5 & 5 & Calvet (2000) \\
\hline$T_{2, \mathrm{~g}}$ & ${ }^{\circ} \mathrm{C}$ & 36 & 36 & 36 & 36 & Calvet (2000) \\
\hline$\tau_{\text {leaf }}$ & $\mathrm{yr}$ & 1 & 1 & 1 & 1 & - \\
\hline$\tau_{\text {stem }}$ & $\mathrm{yr}$ & - & - & 10 & 10 & - \\
\hline$\tau_{\text {root }}$ & $\mathrm{yr}$ & 1 & 1 & 10 & 10 & - \\
\hline$\varphi_{\max }$ & $\mathrm{kgC} \mathrm{m}^{-2}$ & 1 & 1 & 10 & 10 & - \\
\hline
\end{tabular}

The crown area CA is also used to define a root density $\varphi$ [ $\left.\mathrm{kg} \mathrm{C} \mathrm{m}^{-2}\right]$, assuming an equal distribution of root biomass over the crown area according to

$\varphi=\frac{C_{\mathrm{root}}}{\mathrm{CA}}$

which is used to calculate the extractable soil water fraction. Furthermore, it influences the opening of stomata and the surface conductivity (more details in Sect. 2.6). A detailed roof profile is not included in the model, similar to the lack of representing a detailed vertical profile of water.

During the photosynthesis simulation, we calculate NPP (see Appendix B). Then based on Eq. (3), the total biomass is updated, after which vegetation structural variables are updated by equations listed in this section. First, $C_{\text {root }}$ and $C_{\text {leaf }}+C_{\text {stem }}$ can be calculated for known values of $\alpha$ (Eq. 5). Second, $C_{\text {leaf }}+C_{\text {stem }}$ can be represented as a function of LAI and CA by combining Eqs. (6) and (7). Then, LAI and $\mathrm{CA}$ can be retrieved by the combined equations (Eqs. 6 and 7) and and Eq. (8). Third, CA is compared to $\mathrm{CA}_{\text {ref. If }}$ $\mathrm{CA}>\mathrm{CA}_{\text {ref }}$, LAI will be recalculated by the combined equation while keeping $\mathrm{CA}=\mathrm{CA}_{\text {ref }}\left(\mathrm{CA}\right.$ cannot exceed $\left.\mathrm{CA}_{\mathrm{ref}}\right)$. At last, $f_{\mathrm{c}}$ and $\varphi$ can be obtained by Eqs. (9) and (10), respectively.

\subsection{BOSVM model formulation of biomass dynamics and NPP}

The total biomass change is controlled by carbon gain from net primary production (NPP) and carbon loss by litter fall (Eq. 3). NPP is equal to gross primary production (GPP) minus dark respiration $\left(R_{\mathrm{d}}\right)$. GPP is governed by the photosynthetic uptake of carbon, modeled following of the ISBA-A-g model (Jacobs et al., 1996; Calvet, 2000; Calvet et al., 2004) (see Appendix B for a full description of the photosynthesis model).

LIT is parameterized using an exponential decay of the actual biomass using a predefined residence time due to litter decomposition, which is longer for woody plants than for grass (Table 1).

$\mathrm{LIT}=\frac{C_{\text {leaf }}}{\tau_{\text {leaf }}}+\frac{C_{\text {stem }}}{\tau_{\text {stem }}}+\frac{C_{\text {root }}}{\tau_{\text {root }}}$,

where $\tau_{\text {leaf }}, \tau_{\text {stem }}$ and $\tau_{\text {root }}[\mathrm{s}]$ are residence times due to litter decomposition of leaf, stem and root, respectively (Table 1).

As indicated before, NPP is allocated over root, stem and leaf biomass. Three common approaches for NPP allocation exist (Malhi et al., 2011). The simplest way is to use fixed allocation fractions for each carbon pool. Due to different decay timescales for leaf and root (Table 1), the shoot-total biomass ratio $\alpha$ will vary over time as a consequence of this, 
Table 2. Variables in the main text.

\begin{tabular}{|c|c|c|c|c|c|}
\hline Symbols & Unit & Contents & Symbols & Unit & Contents \\
\hline$a_{[\mathrm{v} ; \mathrm{b}]}$ & 1 & $\begin{array}{l}\text { surface albedo of } \\
\text { vegetation (bare ground) }\end{array}$ & $\mathrm{CA}$ & $\mathrm{m}^{2}$ & crown area \\
\hline$C_{\mathrm{veg}}$ & $\mathrm{kgC}$ & biomass of vegetation & $C_{\text {leaf }}$ & $\mathrm{kgC}$ & biomass of leaf \\
\hline$C_{\text {root }}$ & $\mathrm{kgC}$ & biomass of root & $C_{\text {stem }}$ & $\mathrm{kgC}$ & biomass of stem \\
\hline$D$ & $\mathrm{~m}$ & canopy structure factor & $E_{[\mathrm{v} ; \mathrm{b}]}$ & $\mathrm{kg} \mathrm{H}_{2} \mathrm{Om}^{-2} \mathrm{~s}^{-1}$ & evapotranspiration \\
\hline$f_{\mathrm{c}}$ & 1 & leaf coverage & $f_{\mathrm{S}}$ & 1 & relative crown area \\
\hline$f_{\mathrm{w}}, f_{\mathrm{w}}^{*}$ & - & $\begin{array}{l}\text { extractable water factor } \\
\text { with(out) impact of root } \\
\text { density }\end{array}$ & GPP & $\mathrm{kgCm}^{-2} \mathrm{~s}^{-1}$ & gross primary production \\
\hline$G_{[\mathrm{v} ; \mathrm{b}]}$ & $\mathrm{W} \mathrm{m}^{-2}$ & soil heat flux & $g_{\mathrm{a}}$ & $\mathrm{ms}^{-1}$ & $\begin{array}{l}\text { aerodynamic } \\
\text { conductance }\end{array}$ \\
\hline$g_{\mathrm{m}}$ & $\mathrm{ms}^{-1}$ & mesophyll conductance & $g_{\mathrm{s},[\mathrm{v} ; \mathrm{b}]}$ & $\mathrm{m} \mathrm{s}^{-1}$ & surface conductance \\
\hline$H_{[\mathrm{v} ; \mathrm{b}]}$ & $\mathrm{W} \mathrm{m}^{-2}$ & sensible heat flux & $l E_{[\mathrm{v} ; \mathrm{b}]}$ & $\mathrm{W} \mathrm{m}{ }^{-2}$ & latent heat flux \\
\hline LIT & $\mathrm{kgCm}^{-2} \mathrm{~s}^{-1}$ & litter production & LAI & 1 & leaf area index \\
\hline $\operatorname{Leak}_{[1 ; 2]}$ & $\mathrm{kg} \mathrm{H}_{2} \mathrm{O} \mathrm{m}^{-2} \mathrm{~s}^{-1}$ & water leakage & NPP & $\mathrm{kgCm}^{-2} \mathrm{~s}^{-1}$ & net primary production \\
\hline$P_{\mathrm{S}}$ & $\mathrm{Pa}$ & surface pressure & $P$ & $\mathrm{~kg} \mathrm{H}_{2} \mathrm{O} \mathrm{m}^{-2} \mathrm{~s}^{-1}$ & precipitation rate \\
\hline$q_{\mathrm{a}}$ & $\mathrm{Pa}$ & actual vapor pressure & $q_{\mathrm{s}}$ & $\mathrm{Pa}$ & saturated vapor pressure \\
\hline$R_{\mathrm{d}}$ & $\mathrm{kgCm}^{-2} \mathrm{~s}^{-1}$ & dark respiration & $R_{\mathrm{WU}}$ & 1 & relative water use \\
\hline$R_{\text {space }}$ & 1 & relative space of bare soil & $R_{\mathrm{n},[\mathrm{v} ; \mathrm{b}]}$ & $\mathrm{W} \mathrm{m}^{-2}$ & net radiation \\
\hline$R_{\text {lwd }}$ & $\mathrm{W} \mathrm{m} \mathrm{m}^{-2}$ & downward longwave radiation & $R_{\text {swd }}$ & $\mathrm{W} \mathrm{m}^{-2}$ & downward shortwave radiation \\
\hline $\mathrm{SH}$ & $\mathrm{kg} \mathrm{kg}^{-1}$ & specific humidity at $2 \mathrm{~m}$ & $t$ & $\mathrm{~s}$ & simulation time step \\
\hline$T_{\mathrm{a}}$ & $K$ & air temperature at $2 \mathrm{~m}$ & $T_{\mathrm{s},[\mathrm{v} ; \mathrm{b}]}$ & $K$ & surface temperature \\
\hline$T_{[1 ; 2]}$ & $K$ & $\begin{array}{l}\text { temperature of soil layer } 1 \text { and } \\
2\end{array}$ & $u_{\mathrm{n}}$ & $\mathrm{ms}^{-1}$ & $u$ direction wind speed \\
\hline$v_{\mathrm{n}}$ & $\mathrm{ms} \mathrm{s}^{-1}$ & $v$ direction wind speed & $W_{[1 ; 2]}$ & $\mathrm{kg} \mathrm{H}_{2} \mathrm{O}$ & total water stored in soil layers \\
\hline$\alpha$ & 1 & shoot-total biomass ratio & $\theta_{[1 ; 2]}$ & $\mathrm{m}^{3} \mathrm{H}_{2} \mathrm{Om}^{-3}$ & soil moisture \\
\hline$\rho_{\mathrm{a}}$ & $\mathrm{kg} \mathrm{m}^{-3}$ & $\begin{array}{l}\text { mean air density at constant } \\
\text { pressure }\end{array}$ & $\varphi$ & 1 & root density \\
\hline
\end{tabular}

which is not desirable for our purpose. Another approach assumes that NPP allocation is influenced by the availability of resources. For instance, more NPP is allocated to roots under conditions of water and nutrients scarcity, while more NPP is allocated to leaves in light-limited conditions. The method that we used follows LPJ and TRIFFID (Cox, 2001; Sitch et al., 2003), which simulate allocation of NPP by allometric constraints.

Photosynthesis is complex as it is not only determined by environmental elements, but also by the vegetation response to the change of environment. In the $\mathrm{A}-\mathrm{g}_{\mathrm{s}}$ model, the photosynthetic rate is limited by surface temperature, $\mathrm{CO}_{2}$ concentration, water vapor deficit, incoming solar radiation, and available soil moisture (Calvet, 2000; Calvet et al., 2004). In the BOSVM model we specify an effective extractable soil water fraction $f_{\mathrm{w}}$ as a function of soil moisture content and variable root density following

$f_{\mathrm{w}}=\frac{\theta_{2}-\theta_{\text {pwp }}}{\theta_{\text {cap }}-\theta_{\text {pwp }}} \cdot \frac{\varphi}{\varphi_{\text {max }}}$,

where $\theta_{2}\left[\mathrm{~m}^{3} \mathrm{~m}^{-3}\right]$ is volumetric soil moisture content in the root layer (second layer, see bottom right panel of Fig. 1); $\theta_{\text {pwp }}$, and $\theta_{\text {cap }}\left[\mathrm{m}^{3} \mathrm{~m}^{-3}\right]$ are (fixed) soil moisture at wilting point, field capacity, respectively; and $\varphi_{\max }$ is the root density leading to the maximum water uptake ability of plants (Table 1). Available water is thus explicitly dependent on the amount of root biomass.

\subsection{The surface energy balance and geometric structure of the BOSVM model}

In the BOSVM model the energy balance is explicitly simulated for two distinct surface fractions (tiles): a bare ground and a vegetation tile (see bottom right panel of Fig. 1). Vegetation can utilize deep soil water for evapotranspiration, while bare soil has access to a much shallower water reservoir. For this reason we applied a two-soil layer scheme. The depth of the first and second layer is 0.02 and $0.48 \mathrm{~m}$, respectively. Bare soil only can use water from the top layer while vegetation uses the water from the second layer.

Equation (1) can be rewritten for both vegetation and bare soil tiles:

$R_{\mathrm{n},[\mathrm{v} ; \mathrm{b}]}=H_{[\mathrm{v} ; \mathrm{b}]}+l E_{[\mathrm{v} ; \mathrm{b}]}+G_{[\mathrm{v} ; \mathrm{b}]}$. 
Subscript "v" is used for terms that apply to the vegetation tile, while subscript " $\mathrm{b}$ " is used for the bare ground tile.

Net radiation $R_{\mathrm{n},[\mathrm{v} ; \mathrm{b}]}$ is given as

$R_{\mathrm{n},[\mathrm{v} ; \mathrm{b}]}=\left(1-a_{[\mathrm{v} ; \mathrm{b}]}\right) \cdot R_{\mathrm{swd}}+\epsilon \cdot R_{\mathrm{lwd}}-\epsilon \cdot \sigma \cdot T_{\mathrm{s},[\mathrm{v} ; \mathrm{b}]}^{4}$,

where $T_{\mathrm{s},[\mathrm{v} ; \mathrm{b}]}[\mathrm{K}]$ is surface temperature; $a_{[\mathrm{v} ; \mathrm{b}]}[-]$ is surface albedo. For bare ground, $a_{\mathrm{b}}[-]$ is a constant $(0.4)$, while $a_{\mathrm{v}}$ depends on LAI as

$a_{\mathrm{v}}=a_{\min }+\left(a_{\max }-a_{\min }\right) \cdot e^{-k \cdot \mathrm{LAI}}$,

where $a_{\min }=0.1[-]$ and $a_{\max }=0.4[-]$.

Latent heat flux $\left(l E_{[\mathrm{v} ; \mathrm{b}]}\right)$ is given by

$l E_{[\mathrm{v} ; \mathrm{b}]}=l \rho_{\mathrm{a}} \frac{q_{\mathrm{s}}\left(T_{\mathrm{s},[\mathrm{v} ; \mathrm{b}]}\right)-q_{\mathrm{a}}}{1 / g_{\mathrm{a}}+1 / g_{\mathrm{s},[\mathrm{v} ; \mathrm{b}]}}$,

where $l\left[\mathrm{~J} \mathrm{~kg} \mathrm{H}_{2} \mathrm{O}^{-1}\right]$ is latent heat of vaporization; $\rho_{\mathrm{a}}$ $\left[\mathrm{kg} \mathrm{m}^{-3}\right]$ is air density at constant pressure; $g_{\mathrm{a}}\left[\mathrm{m} \mathrm{s}^{-1}\right]$ is aerodynamic conductance; $g_{\mathrm{s},[\mathrm{v} ; \mathrm{b}]}\left[\mathrm{m} \mathrm{s}^{-1}\right]$ is surface conductance; $q_{\mathrm{s}}[\mathrm{Pa}]$ is surface-saturated specific humidity, $q_{\mathrm{a}}[\mathrm{Pa}]$ is air specific humidity.

For vegetation, $g_{\mathrm{s}, \mathrm{v}}$ is equal to the canopy conductance (see Appendix B), while for bare ground $g_{\mathrm{s}, \mathrm{b}}$ is given by,

$g_{\mathrm{s}, \mathrm{b}}=g_{\mathrm{s}, \max } \cdot f_{\mathrm{w}}^{*}$

where $g_{\mathrm{s}, \max }\left[\mathrm{m} \mathrm{s}^{-1}\right]$ is the maximum surface conductance of bare soil; and $f_{\mathrm{w}}^{*}[-]$ is extractable water factor of bare ground given by,

$f_{\mathrm{w}}^{*}=\frac{\theta_{1}-\theta_{\mathrm{r}}}{\theta_{\text {cap }}-\theta_{\mathrm{r}}}$,

where $\theta_{1}\left[\mathrm{~m}^{3} \mathrm{~m}^{-3}\right]$ is soil moisture from the top soil layer (first layer), $\theta_{\mathrm{r}}=0.01\left[\mathrm{~m}^{3} \mathrm{~m}^{-3}\right]$ is residual soil moisture.

Sensible heat flux is calculated as

$H_{[\mathrm{v} ; \mathrm{b}]}=\rho_{\mathrm{a}} c_{p} g_{\mathrm{a}}\left(T_{\mathrm{s},[\mathrm{v} ; \mathrm{b}]}-T_{\mathrm{a}}\right)$,

where $c_{p}\left[\mathrm{~J} \mathrm{~kg}^{-1} \mathrm{~K}^{-1}\right]$ is the specific heat capacity of air; and $T_{\mathrm{a}}[K]$ is air temperature at $2 \mathrm{~m}$.

The soil heat flux is defined as

$G_{[\mathrm{v} ; \mathrm{b}]}=-2 C_{1} \frac{T_{1}-T_{\mathrm{s},[\mathrm{v} ; \mathrm{b}]}}{z_{1}}$,

where $C_{1}\left[\mathrm{~W} \mathrm{~m}^{-1} \mathrm{~K}^{-1}\right]$ is the thermal conductivity of the soil; $T_{1}[\mathrm{~K}]$ is the soil temperature of the top soil layer; $z_{1}$ $[0.02 \mathrm{~m}]$ is the depth of the first layer. All fluxes are defined as positive downward.

We calculate separate surface temperatures for bare ground and vegetation. However, the soil temperature is identical for the two tiles. Heat flux exchanges between the surface and layer 1 are given by $G_{[v ; b]}$, while between layer 1 and 2 the heat conductance is parameterized. We assume a zero flux boundary condition below the second layer. The numerical method to update soil temperature is discussed in Appendix C.

\subsection{Water balance}

As shown in Fig. 1, soil water is recharged by precipitation and can be lost by evapotranspiration and leakage. Consistent with the tiling and two-soil layer structure, the water balance equation can be written as

$$
\begin{aligned}
& \frac{\mathrm{d} W_{1}}{\mathrm{~d} t}=z_{1} \cdot \mathrm{CA}_{\text {ref }} \frac{\mathrm{d} \theta_{1}}{\mathrm{~d} t}= \\
& \left(P-\mathrm{Leak}_{1}-E_{\mathrm{b}} \cdot\left(1-f_{\mathrm{c}}\right)\right) \mathrm{CA}_{\text {ref }} \\
& \frac{\mathrm{d} W_{2}}{\mathrm{~d} t}=z_{2} \cdot \mathrm{CA}_{\mathrm{ref}} \frac{\mathrm{d} \theta_{2}}{\mathrm{~d} t}= \\
& \left(\text { Leak }_{1}-\text { Leak }_{2}-E_{\mathrm{v}} \cdot f_{\mathrm{c}}\right) \mathrm{CA}_{\text {ref }},
\end{aligned}
$$

where $W_{[1 ; 2]}\left[\mathrm{kg} \mathrm{H}_{2} \mathrm{O}\right]$ is the total water stored in layer 1 and 2; $P\left[\mathrm{~kg} \mathrm{H}_{2} \mathrm{O} \mathrm{m}^{-2} \mathrm{~s}^{-1}\right]$ is the precipitation rate; $\operatorname{Leak}_{[1 ; 2]}$ $\left[\mathrm{kg} \mathrm{H}_{2} \mathrm{O} \mathrm{m}^{-2} \mathrm{~s}^{-1}\right]$ is water leakage from surface to soil layer 1 , and out of the second soil layer to the deep ground, respectively; and $z_{2}[0.48 \mathrm{~m}]$ is the depth of the second soil layer.

Surface runoff is not considered explicitly. Instead, we assume that precipitation will infiltrate directly into the second soil layer when soil moisture in the top layer reaches field capacity. Other details are in Appendix D. As the effects of soil type are not taken into account in this study, we keep parameters of soil properties as constants.

\subsection{Soil moisture effects on water use efficiency for the two-soil water stress strategies}

In the BOSVM, we include the impact of soil moisture on photosynthesis activity. Observations show that plants can adopt different strategies to cope with drought by controlling their stomata (Calvet, 2000; Calvet et al., 2004). During drought, a class of plants (e.g., soybean, maritime pine; Calvet, 2000; Calvet et al., 2004) close their stomata to decrease transpiration, but increase mesophyll conductance $\left(g_{\mathrm{m}}\right.$ $\left.\left[\mathrm{m} \mathrm{s}^{-1}\right]\right)$ to sustain photosynthesis. Another class of plants (e.g., hazel tree, sunflower, sessile oak, Calvet, 2000; Calvet et al., 2004) leave their stomata open for transpiration and decrease the mesophyll conductance. After the soil moisture drops below a threshold, both types start to close stomata and stop carbon assimilation. These strategies affect biomass accumulation significantly and determine different water use efficiencies (WUE) (Eq. 23). More details are described in Calvet (2000) and Calvet et al. (2004). Here we only discuss the relationship between water use efficiency and extractable soil water content.

$\mathrm{WUE}=\frac{\mathrm{GPP}}{E_{\mathrm{V}}}$

Following the parameterization of Calvet (2000) and Calvet et al. (2004), Fig. 2 presents the simulated intrinsic water use efficiency (ratio of net assimilation $A_{\mathrm{n}}$ to stomatal conductance $g_{\mathrm{s}}$ ) for two strategies of grass and woody plants as a function of extractable soil water. 


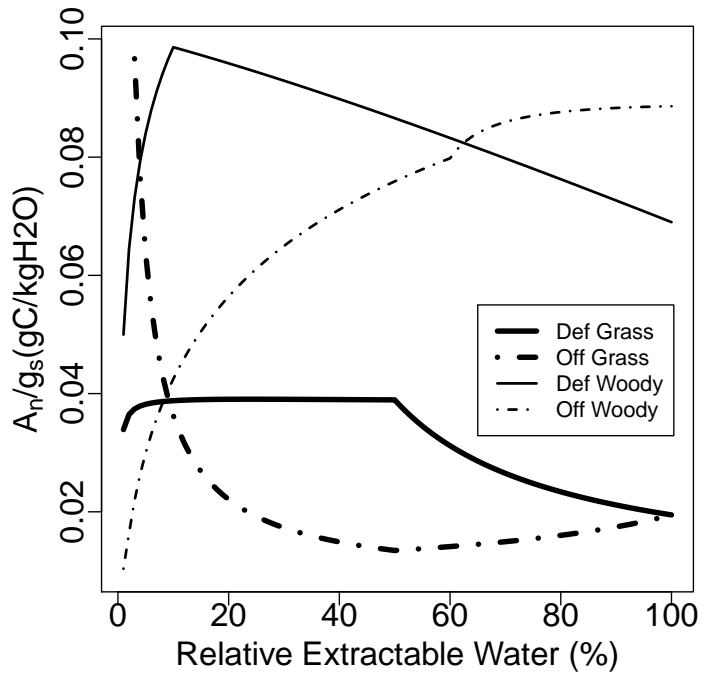

Fig. 2. Intrinsic WUE as a function of extractable water. Extractable water $\left(f_{\mathrm{W}}\right)$ is defined as Eq. (12). Solid and dot-dashed lines represent defensive and offensive strategies, respectively. Thick and thin lines represents grass and woody plants, respectively. $\mathrm{vpD}=12 \mathrm{~g} \mathrm{~kg}^{-1}, \mathrm{LAI}=1, R_{\text {swd }}=800 \mathrm{~W} \mathrm{~m}^{-2}, c_{\mathrm{a}}=380 \mathrm{ppm}$ and $T_{\mathrm{S}}=25^{\circ} \mathrm{C}$.

In the defensive case, both woody plants and grasses increase WUE when extractable water decreases. Stomata close and $g_{\mathrm{m}}$ increases (grass) or maintains (woody) its value. This regime extends until extractable water falls below an (observation-based) threshold, from where $g_{\mathrm{m}}$ decreases sharply. The offensive case is more complex. Offensive plants insist on maintaining their stomatal opening until very dry conditions are encountered, which is based on the parameterization (Table 1). For woody vegetation, $g_{\mathrm{m}}$ then drops dramatically, which leads to a decrease in photosynthesis and consequently a decrease of WUE. However, $g_{\mathrm{m}}$ of grass remains relatively constant, which results in a smaller decrease of WUE.

In general, woody plants have a higher water use efficiency than grass. Although WUE of defensive woody vegetation is inversely proportional to soil water content when extractable soil water fractions exceed $10 \%$, it is still larger than WUE of offensive woody vegetation until extractable water content exceeds $60 \%$, which is rarely met in arid and semi-arid regimes. Therefore, we assume that the WUE of defensive woody vegetation strategy is always higher than offensive woody vegetation strategy.

\subsection{Potential impacts of structural vegetation parameters on biomass amount}

In this study, we explore how vegetation adapts to climate via optimizing its spatial structure ( $\alpha$ and $D$ ). We assume that the objective of the adaption is that vegetation tries to maximize its total biomass, which is the goal function

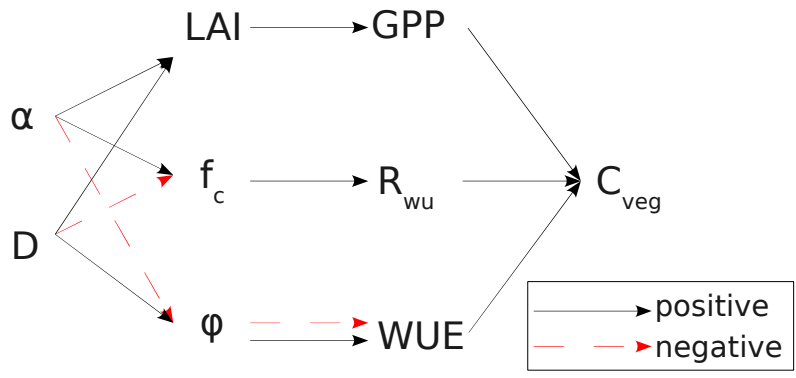

Fig. 3. Impacts of $\alpha$ and $D$ on vegetation biomass via six variables. Solid (black) and dashed (red) lines represent positive and negative impact, respectively. $R_{\mathrm{WU}}$ is the relative water use, defined in Eq. (25). $\varphi$ is root density. WUE is water use efficiency as defined in Eq. (23).

$\operatorname{Max}\left(C_{\mathrm{veg}}\right)=f(\alpha, D)$.

To maximize the total biomass, vegetation structure parameters $(\alpha$ and $D)$ need to be optimized. $\alpha$ and $D$ cannot influence $C_{\text {veg }}$ directly, but determine $C_{\text {veg via a collection }}$ of intermediate variables in the carbon-water-energy cycles.

Using the vegetation structure as defined by the parameterization of the BOSVM, we illustrate the potential impacts of two structural parameters on total biomass. Biomass amount is updated by carbon gain and carbon loss processes. In the BOSVM, carbon loss is set equal to litter fall (Eq. 3). Since the involved timescales $\tau_{\text {leaf }}, \tau_{\text {stem }}$ and $\tau_{\text {root }}$ (Eq. 11) are constants, vegetation structure does not affect carbon loss. The amount of carbon gain (NPP) is limited by water and light, where light absorption is directly related to LAI. Concerning the water component, the carbon gain is not only influenced by the degree to which net photosynthesis is governed by available soil water, but also by the ability of vegetation to use water from the neighboring bare ground fraction, which can be represented by the relative water use $\left(R_{\mathrm{WU}}\right) . R_{\mathrm{WU}}$ is the ratio of vegetation transpiration over total evapotranspiration, defined as

$R_{\mathrm{WU}}=\frac{E_{\mathrm{v}} \cdot f_{\mathrm{c}}}{E_{\mathrm{v}} \cdot f_{\mathrm{c}}+E_{\mathrm{b}} \cdot\left(1-f_{\mathrm{c}}\right)}$.

From the definition (Eq. 25), we can find that $R_{\mathrm{WU}}$ is highly dependent on $f_{\mathrm{c}}$. Notice that $R_{\mathrm{WU}}$ is not equal to rain use efficiency, because water also can be lost by infiltrating deeper soil layers.

WUE depends on extractable soil water content $\left(f_{\mathrm{W}}\right)$ (Sect. 2.6). From the definition of $f_{\mathrm{w}}$ (Eq. 12), it is clear that $f_{\mathrm{w}}$ is affected by $\varphi$ with given soil moisture.

Figure 3 presents the conceptual relation between structural parameters ( $\alpha$ and $D$ ), vegetation internal factors (LAI, $f_{\mathrm{c}}, \varphi$, GPP and WUE), $R_{\mathrm{WU}}$ and total biomass. From Fig. 3 , we can find that $\alpha$ has a positive relationship with both LAI and $f_{\mathrm{c}}$, as a higher $\alpha$ implies higher aboveground biomass 
Table 3. Constants in the main text.

\begin{tabular}{|c|c|c|c|c|c|}
\hline Symbols & Value & Contents & Symbols & Value & Contents \\
\hline$a$ & 1.6 & $\begin{array}{l}\text { diffusivity constants of } \\
\mathrm{H}_{2} \mathrm{O} \text { and } \mathrm{CO}_{2}\end{array}$ & $a_{b}$ & 0.4 & albedo of bare ground \\
\hline$a_{\max }$ & 0.4 & $\begin{array}{l}\text { maximum albedo of } \\
\text { vegetation }\end{array}$ & $a_{\min }$ & 0.1 & $\begin{array}{l}\text { minimum albedo of } \\
\text { vegetation }\end{array}$ \\
\hline $\mathrm{CA}_{\text {ref }}$ & $15 \mathrm{~m}^{2}$ & maximum crown area & $c_{p}$ & $1013 \mathrm{~J} \mathrm{~kg}^{-1} \mathrm{~K}^{-1}$ & $\begin{array}{l}\text { specific heat capacity } \\
\text { of air }\end{array}$ \\
\hline$g_{\mathrm{s}, \max }$ & $0.2 \mathrm{~m} \mathrm{~s}^{-1}$ & $\begin{array}{l}\text { maximum bare ground } \\
\text { conductance }\end{array}$ & $\mathrm{LAI}_{\text {ref }}$ & 6 & referred LAI \\
\hline$l$ & $2.45 \times 10^{6} \mathrm{~J} \mathrm{~kg}^{-1}$ & latent heat of vaporization & SLA & $20 \mathrm{~m}^{2} \mathrm{~kg}^{-1}$ & specific leaf area \\
\hline$z_{[1 ; 2]}$ & $0.02 ; 0.48 \mathrm{~m}$ & depth of layer $1(2)$ & $\epsilon$ & 0.96 & surface emissivity \\
\hline$\theta_{\text {pwp }}$ & 0.151 & $\begin{array}{l}\text { soil moisture at wilting } \\
\text { point }\end{array}$ & $\theta_{\text {cap }}$ & 0.346 & $\begin{array}{l}\text { soil moisture at field } \\
\text { capacity }\end{array}$ \\
\hline$\theta_{\mathrm{r}}$ & 0.01 & residual soil moisture & $\theta_{\text {sat }}$ & 0.439 & saturated soil moisture \\
\hline$\sigma$ & $5.67 \times 10^{-8} \mathrm{~W} \mathrm{~m}^{-2} \mathrm{~K}^{-4}$ & $\begin{array}{l}\text { Stefan-Boltzmann } \\
\text { constant }\end{array}$ & & & \\
\hline
\end{tabular}

(Eq. 5). $\varphi$ declines with an increasing $\alpha$ due to larger CA and lower values of $C_{\text {root }}$ (Eq. 10). The canopy structure parameter $D$ has a positive impact on LAI and conversely a negative impact on $f_{\mathrm{c}}$, since a high value of $D$ represents a lower crown area. Therefore $D$ is positively related to $\varphi$ for a given value of $\alpha$.

A high LAI increases the absorption of light per unit area, which results in a higher GPP. In our two-soil layer scheme (described in Sect. 2.5), bare soil evaporation is only extracted from the top layer. A higher $f_{\mathrm{c}}$ reduces water loss from bare soil $\left(E_{\mathrm{b}}\left(1-f_{\mathrm{c}}\right)\right.$ in Eq. (25) becomes smaller), which in turn implies that $f_{\mathrm{c}}$ has a positive effect on $R_{\mathrm{WU}}$. A higher $f_{\mathrm{c}}$ also implies that the water taken from the bare ground has to be distributed over a larger vegetated area, which imposes a negative effect. This can be expressed by defining $R_{\text {space, }}$, which describes this water distribution fraction.

$R_{\text {space }}=\frac{1-f_{\mathrm{c}}}{f_{\mathrm{c}}}$

$\varphi$ can have both a positive and a negative impact on WUE, depending on photosynthesis strategies and water content (Sect. 2.6). For offensive grass, a negative relation between $\varphi$ and WUE is present. For other vegetation types, the relation is generally positive. Although WUE decreases when extractable water content exceeds a certain threshold, the magnitude of this reduction is relatively low (see Fig. 2).

\subsection{Simulation process}

Figure 4 illustrates the chain of computations followed in the BOSVM model simulation process. The model state variables to be initialized are total biomass, soil moisture and soil temperature in two layers, and a number of vegetation structure factors before spin up. The initial total biomass is set to $30 \mathrm{kgC}$ to avoid vegetation extinction at

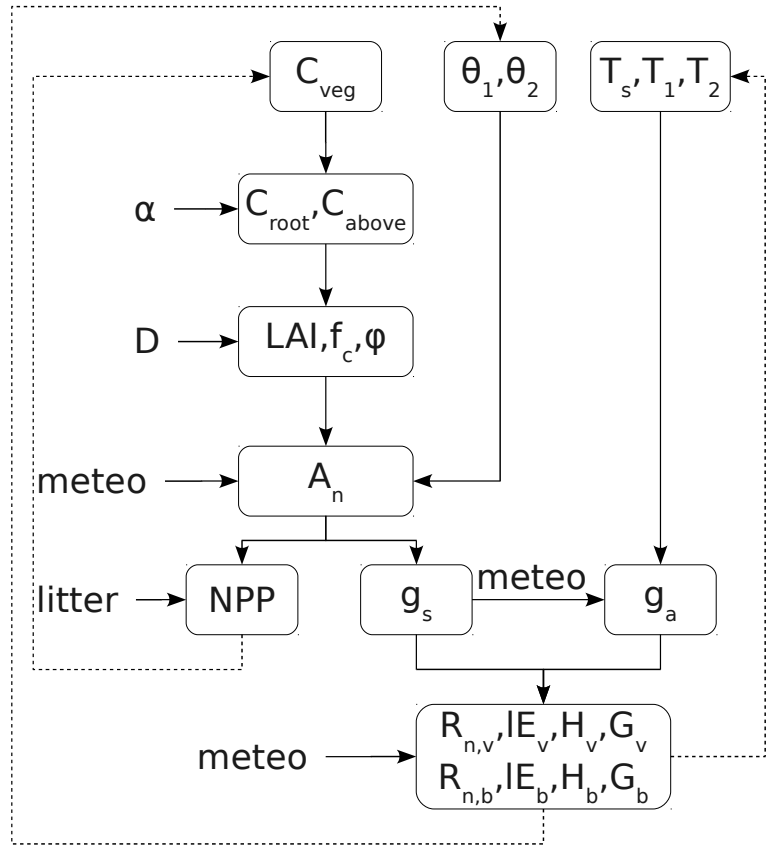

Fig. 4. Flow diagram of the model. Dashed arrows imply time step updates. For symbols see text.

the start of the simulation. Initial soil moisture in both layers is equal to saturated soil moisture. Initial soil temperature of the two layers is equal to the initial air temperature. Model parameter $\alpha$ controls the distribution of total biomass over aboveground $\left(C_{\text {leaf }}+C_{\text {stem }}\right)$ and belowground $\left(C_{\text {root }}\right)$ biomass (Eq. 5). For woody vegetation the aboveground biomass is distributed over $C_{\text {leaf }}$ and $C_{\text {stem. }}$. The geometrical distribution of leaf biomass is governed by a trade-off 
between high LAI concentrated on a relatively small crown area (CA) or low LAI combined with higher CA. The structure parameter $D$ controls this trade-off (Eqs. 7 and 8). Once CA and LAI are known (see method in Sect. 2.2), the vegetation fraction $\left(f_{\mathrm{c}}\right)$ and root density $(\varphi)$ can be specified (Eqs. 9 and 10). $f_{\mathrm{c}}$ is used to define two adjacent tiles (one vegetated, one bare ground) for which separate energy balances are computed.

The next step is the calculation of the photosynthesis process, which eventually leads to the specification of the stomatal conductance $\left(g_{\mathrm{s}}\right)$ and the biomass gain. Inputs for this photosynthesis calculation are the meteorological forcing, soil moisture conditions and the vegetation structure parameters. From soil water content and relative root density we can calculate the mesophyll conductance $\left(g_{\mathrm{m}}\right)$ and internal $\mathrm{CO}_{2}$ concentration (different approaches used for woody plants and grass, and for defensive or offensive soil moisture strategy) as specified in Appendix A. The photosynthesis rate depends on temperature (Appendix $\mathrm{B} 1$ ), internal $\mathrm{CO}_{2}$ concentration, mesophyll conductance (Appendix $\mathrm{B} 2$ ) and radiation (Appendix B3). From the photosynthetic $\mathrm{CO}_{2}$ flux (corrected for dark respiration) and the gradient of $\mathrm{CO}_{2}$ between the ambient atmosphere and the internal concentration, the stomatal conductance can be calculated (Eqs. B10 and B11). This stomatal conductance is upscaled to the canopy scale by applying a vertical integration over the LAI profile (Appendix B4).

The aerodynamic exchange coefficient $\left(g_{\mathrm{a}}\right)$ is calculated using the Monin-Obukhov similarity theory (Appendix C1). From the meteorological forcing and the aerodynamic and canopy conductance, the energy balance in each tile can be found by solving for the surface temperature (Eqs. 13-20).

The final step in the procedure is the update of the state variables. Vegetation carbon content is updated by the biomass gain from the photosynthesis, and a mortality governed by the litter fall parameterization (Eq. 11). After updating the $C_{\mathrm{veg}}$, other structural variables can be updated according to the method described in Sect. 2.2. The evapotranspiration rate found in the energy balance algorithm is used to adjust the water balance (Appendix D), while the soil heat flux modifies the soil temperature (Appendix C2). The time step $(\mathrm{d} t)$ of the simulation is half an hour for all processes.

\subsection{Study area and data sets}

The BOSVM model has been set up for a grid configuration covering West Africa, where a large climate gradient exists (see Fig. 5). The model is set up at a $0.5^{\circ}$ grid and forced using 3 hourly values of incoming longwave and shortwave radiation, precipitation, air temperature, wind speed and humidity for the period 2002 to 2007. The data are generated in the AMMA Land Model Intercomparison Project (Boone et al., 2009), and were used to run and compare a range of land surface models. In this data set, at $10^{\circ} \mathrm{E}, 15^{\circ} \mathrm{N}$ the maximum annual precipitation is approximately $200 \mathrm{~mm} \mathrm{yr}^{-1}$,
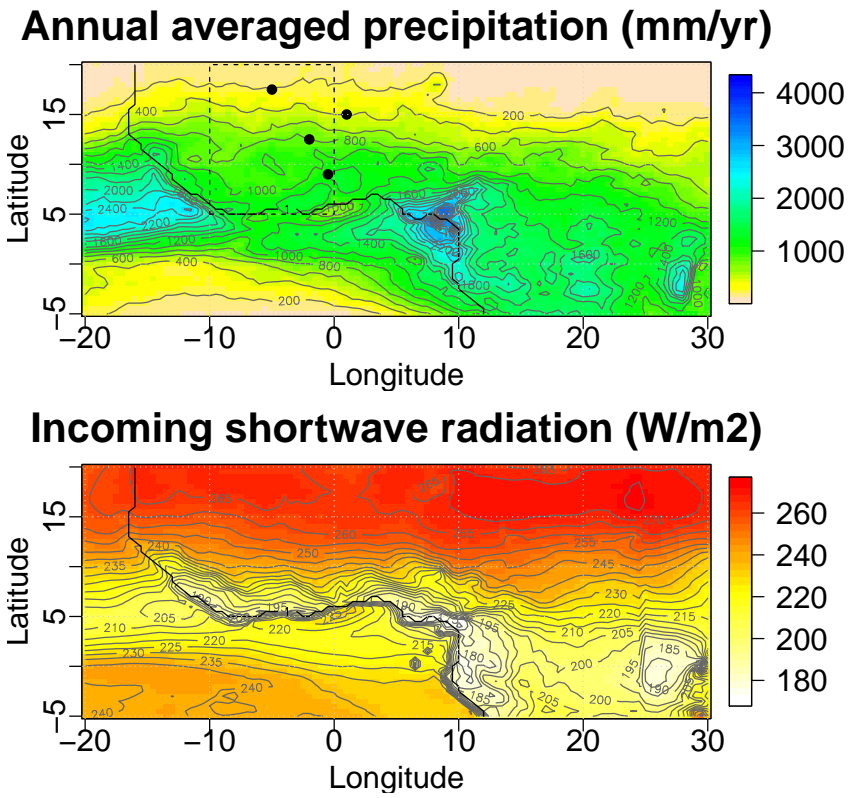

Fig. 5. Annual mean precipitation and incoming shortwave radiation distribution in West Africa. The four black points are chosen as climate forcings in the second experiment (Sect. 3.2). The rectangle marked is the study domain in the third experiment (Sect. 3.3), ranging from $20^{\circ} \mathrm{W}, 30^{\circ} \mathrm{E}$ to $5^{\circ} \mathrm{S}, 20^{\circ} \mathrm{N}$ in West Africa. Data are from the ALMIP forcing data set (Boone et al., 2009).

while it increases to $4000 \mathrm{~mm} \mathrm{yr}^{-1}$ near the coast. Shortwave incoming radiation shows an opposite gradient, reducing from $270 \mathrm{~W} \mathrm{~m}^{-2}$ at $20^{\circ} \mathrm{N}$ to $170 \mathrm{~W} \mathrm{~m}^{-2}$ near the coast at $5^{\circ} \mathrm{N}$.

Since this study focuses on the effect of vegetation structure on total biomass across a precipitation gradient, the BOSVM model is only applied to a subset of all locations in West Africa. In the second experiment (Sect. 3.2), four grid cells with mean annual precipitation of $200 \mathrm{~mm} \mathrm{yr}^{-1}$, $400 \mathrm{~mm} \mathrm{yr}^{-1}, 800 \mathrm{~mm} \mathrm{yr}^{-1}$ and $1200 \mathrm{~mm} \mathrm{yr}^{-1}$ (black points in Fig. 5) are chosen as climate forcing to represent the gradient of rainfall. In the third experiment (Sect. 3.3), we provide the model simulation for a subregion (the dashed rectangle in Fig. 5).

The chosen value of the litter timescale ( 10 years) leads to variations of biomass of woody plants at the decadal timescale. For particular vegetation structures and climate conditions, biomass changes are very slow. A 300-year simulation is found to be adequate to approach equilibrium state for all types of vegetation structures. We spin up the BOSVM model by a repeated simulation of at least 20 times the available 6-year forcing record (for some specific structures, 50 times is needed), and present results deduced from a mean annual cycle for the simulated 6 years following the spin-up period. In this way, we calculate equilibrium biomass and other state variables and fluxes. 

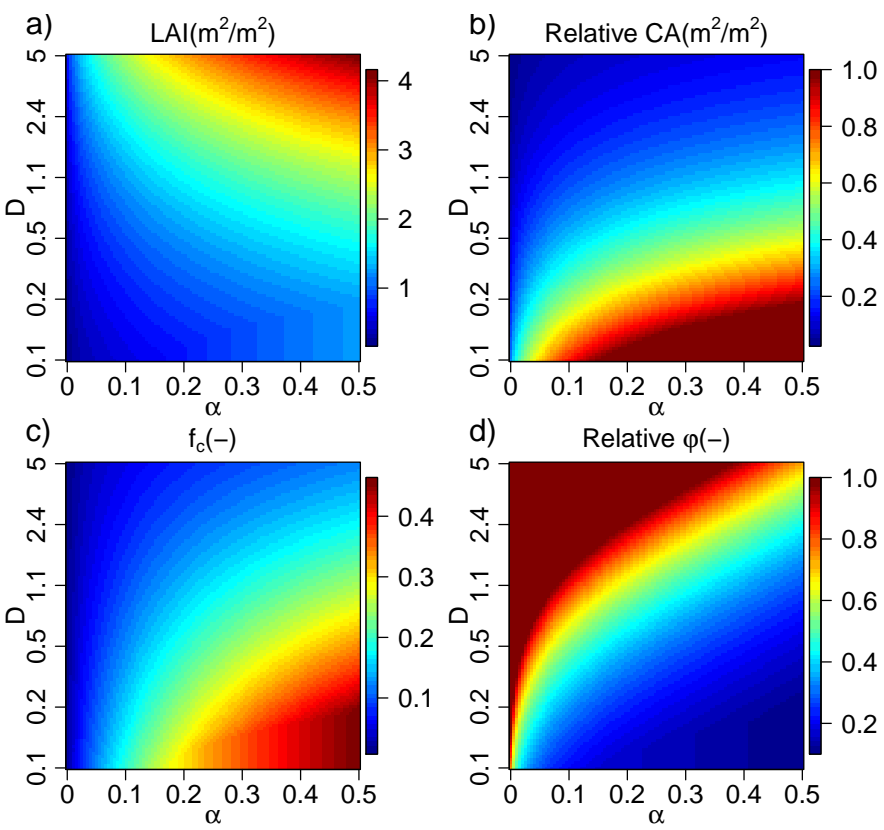

Fig. 6. Patterns of woody vegetation for different combinations of $\alpha$ and $D$. $\alpha$ is varied from 0 to 0.5 . $D$ is set from 0.1 to 5 . Total biomass is $30 \mathrm{~kg} \mathrm{C}$ per pixel of $15 \mathrm{~m}^{2}$. Panel (a): LAI; (b): relative CA; (c): $f_{\mathrm{c}}$; (d): relative $\varphi$. Relative CA is defined as CA/CA ref. Relative $\varphi$ is defined as $\varphi / \varphi_{\max }$. When $\varphi>\varphi_{\max }$, value of relative $\varphi$ is set to 1 . The scale of $D$ ( $y$ axis) follows an inverse tangent function. Same for Figs. 7 to 9 .

\section{Results}

\subsection{Sensitivity of vegetation structure to $\alpha$ and $D$}

To illustrate the sensitivity of vegetation structure to $\alpha$ and $D$, Fig. 6 shows values of LAI, $f_{\mathrm{c}}$, relative CA and relative $\varphi$ for a range of $\alpha$ and $D$ values, assuming a woody vegetation type with constant vegetation biomass $C_{\mathrm{veg}}=30 \mathrm{~kg} \mathrm{C}$ for the whole $\mathrm{CA}_{\text {ref }}$ of $15 \mathrm{~m}^{2}$.

LAI increases with both $\alpha$ and $D$ (Sect. 2.7). Once CA is equal to $\mathrm{CA}_{\text {ref, }} \mathrm{LAI}$ has a positive linear relation with $\alpha$ (see bottom left corner of Fig. 6a).

CA and LAI are negatively related for a given amount of leaf biomass (Fig. 6a and b show opposite slopes with certain $\alpha$ ). Both LAI and CA are more sensitive to $D$ when $\alpha>0.1$. Maximum CA appears with high $\alpha$ and low $D$. When $D$ is extremely low, $\mathrm{CA}_{\text {ref }}$ can be reached by allocating a little amount of leaf biomass. When $\alpha>0.2, \mathrm{CA}$ is dominated by $D$ due to higher leaf biomass.

$f_{\mathrm{c}}$ (Fig. 6c) is dominated by CA. However, it is also affected by LAI (Eq. 9), especially when LAI is low. Maximum $f_{\mathrm{c}}$ appears with high $\alpha$ and low $D$. Patterns of CA and $f_{\mathrm{c}}$ are similar, but $f_{\mathrm{c}}$ is more sensitive to $\alpha$, which has positive relations with both CA and LAI (Fig. 3).

$\varphi$ affects the water uptake ability of vegetation (Appendix B). If $C_{\text {veg }}$ is given, $\varphi$ depends on $\alpha$ and CA (Eq. 10). In Fig. 6d, a maximum root density is found with small $\alpha$ and high $D$, leading to a large rooting biomass and small crown area.

\subsection{Optimal vegetation structure}

In this section we simulate how vegetation structure and soil water stress influence biomass, LAI, $f_{\mathrm{c}}$, water use efficiency and relative water use ( $\left.R_{\mathrm{WU}}\right)$. Ten $\alpha$ and $10 D$ are chosen to compose an ensemble of 100 vegetation structures. With these ensembles, two-soil water stress strategies are applied to four precipitation regimes $(200,400,800$ and $1200 \mathrm{~mm} \mathrm{yr}^{-1}$, all ranging within $\pm 25 \mathrm{~mm} \mathrm{yr}^{-1}$ ) in West Africa. In each regime approximately five grid points were randomly collected. Here we show simulations for offensive and defensive grass for the $200 \mathrm{~mm} \mathrm{yr}^{-1}$ climate regime, and woody plant structures for all four climate regimes. The intrinsic WUE of defensive strategy for woody plants is always higher than that of offensive strategy under same situation (Calvet et al., 2004), which implies that the defensive strategy leads to more biomass than the offensive strategy with each specific structure. For this reason only the defensive strategy is illustrated for woody plants.

\subsubsection{Grass biomass dynamics for $200 \mathrm{~mm} \mathrm{yr}^{-1}$}

Figure 7a shows the sensitivity of the equilibrium biomass amount for grass as a function of $\alpha$ and $D$ in the $200 \mathrm{~mm} \mathrm{yr}^{-1}$ precipitation regime for the defensive strategy. Figure $7 \mathrm{~b}$ shows relations of $C_{\mathrm{veg}}-\mathrm{LAI}, C_{\mathrm{veg}}-f_{\mathrm{c}}, C_{\mathrm{veg}}-\mathrm{WUE}$ and $f_{\mathrm{c}}-$ $R_{\mathrm{WU}}$. Each cross corresponds to a specific vegetation structure. Related Spearman correlation coefficients are displayed in each subfigure. The maximum biomass appears with the 

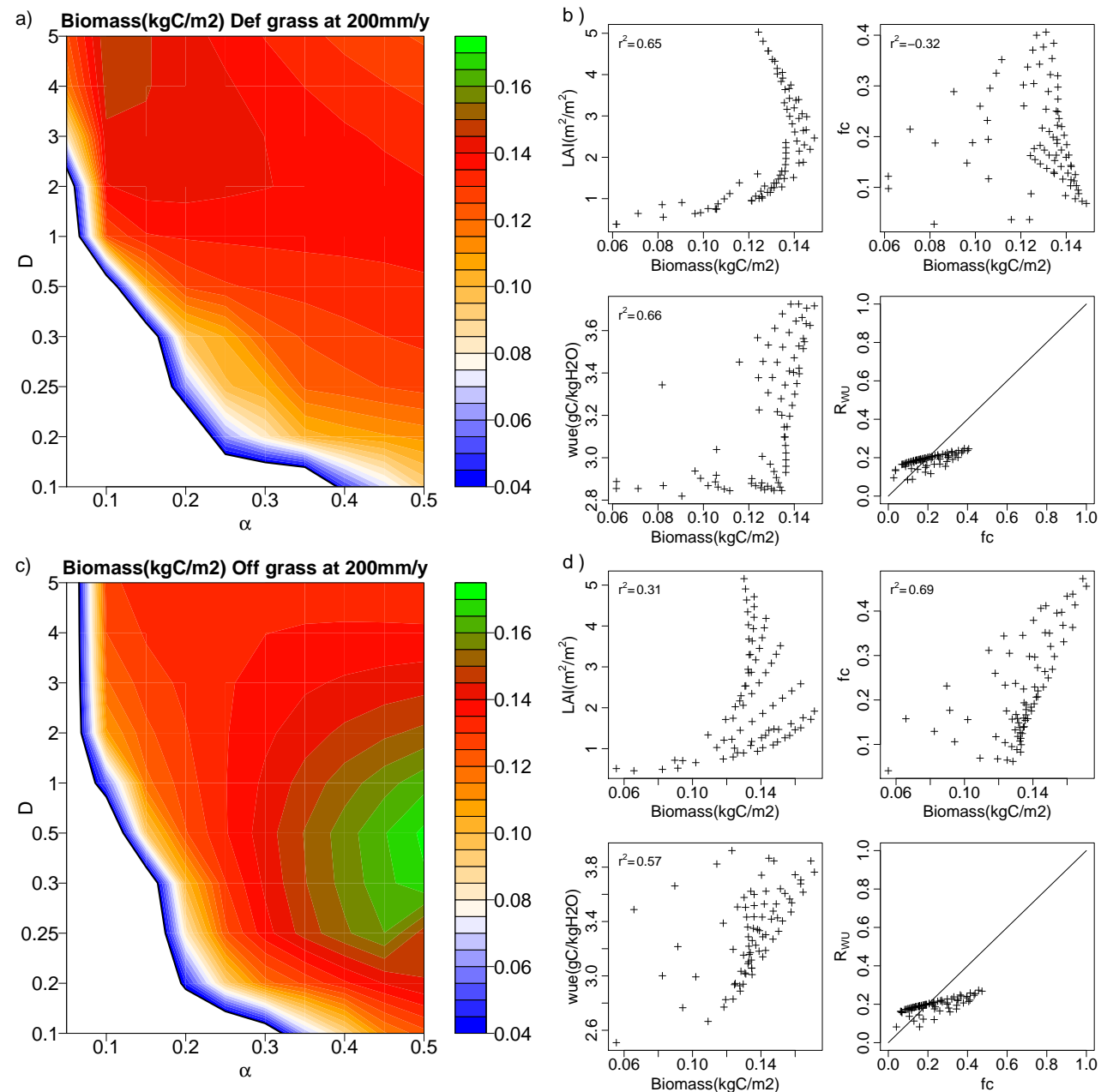

Fig. 7. Sensitivity analysis of equilibrium biomass to vegetation structure: A. Panels (a) and (c) present 6-year averaged total biomass that changes with different vegetation structures of two strategies. Patterns represent survival structures under the specified regime. Panels (b) and (d) display several variables (LAI, $f_{\mathrm{c}}$ and WUE) as a function of biomass and a comparison between $f_{\mathrm{c}}$ and $R_{\mathrm{WU}}$. Solid lines in panels (b) and (d) are identity line. Panels (a) and (b) are for the defensive grass case under $200 \mathrm{~mm} \mathrm{yr}^{-1}$. Panels (c) and (d) are for the offensive grass case.

maximum $D$, which implies a high LAI $\left(2.5 \mathrm{~m}^{2} \mathrm{~m}^{-2}\right)$ and a very low $f_{\mathrm{c}}$ of 0.06 , indicating patches of dense grasses. For defensive grasses, the water use efficiency increases with extractable water (Sect. 2.6 and Fig. 2), implying low $\alpha$ is more optimal. However, for low values of $\alpha(<0.1)$, LAI is too low to gain enough carbon to sustain a high root density. A tradeoff exists between root density and LAI. Thus the maximum biomass is found for intermediate shoot-total biomass ratio $(\alpha=0.15)$. This also can be seen in Fig. 3. $\alpha$ has positive and negative impacts on GPP and WUE, respectively, which implies that a trade-off exists. Meanwhile, $D$ has a positive effect on both GPP and WUE, implying that the maximum $D$ is optimal. The simulated biomass is more strongly correlated with WUE and LAI than with $f_{\mathrm{c}}$ (Fig. 7b). We conclude that for dry conditions WUE is more important to biomass than $f_{\mathrm{c}}$. Moreover, it is interesting to note that the relative water use $\left(R_{\mathrm{WU}}\right)$ of the optimized patches $\left(f_{\mathrm{c}}=0.06\right.$ and $C_{\text {veg }}=0.13 \mathrm{~kg} \mathrm{C}$ ) is higher than $f_{\mathrm{c}}$. This implies that water is extracted from the surrounding bare soil to supply the transpiration from the vegetated fraction of the area.

The biomass patterns of offensive grasses (Fig. 7c and d) are clearly different from defensive grasses. In the offensive case, WUE decreases with increasing extractable water (Fig. 2). Since $\varphi$ has a negative impact on WUE, the maximum biomass is found with the highest $\alpha$, which positively affects both WUE and GPP (Fig. 3). Whereas $D$, in turn, has negative relation to WUE but positive relation to GPP. Therefore a medium value of $D$ is found with maximum biomass. Simultaneously, decreasing $D$ increases vegetation cover (based on the definition of $D$ in Eq. 8) and thereby reduces the extraction of water from the surrounding soil to the vegetation. From Fig. 7d, we can find that 

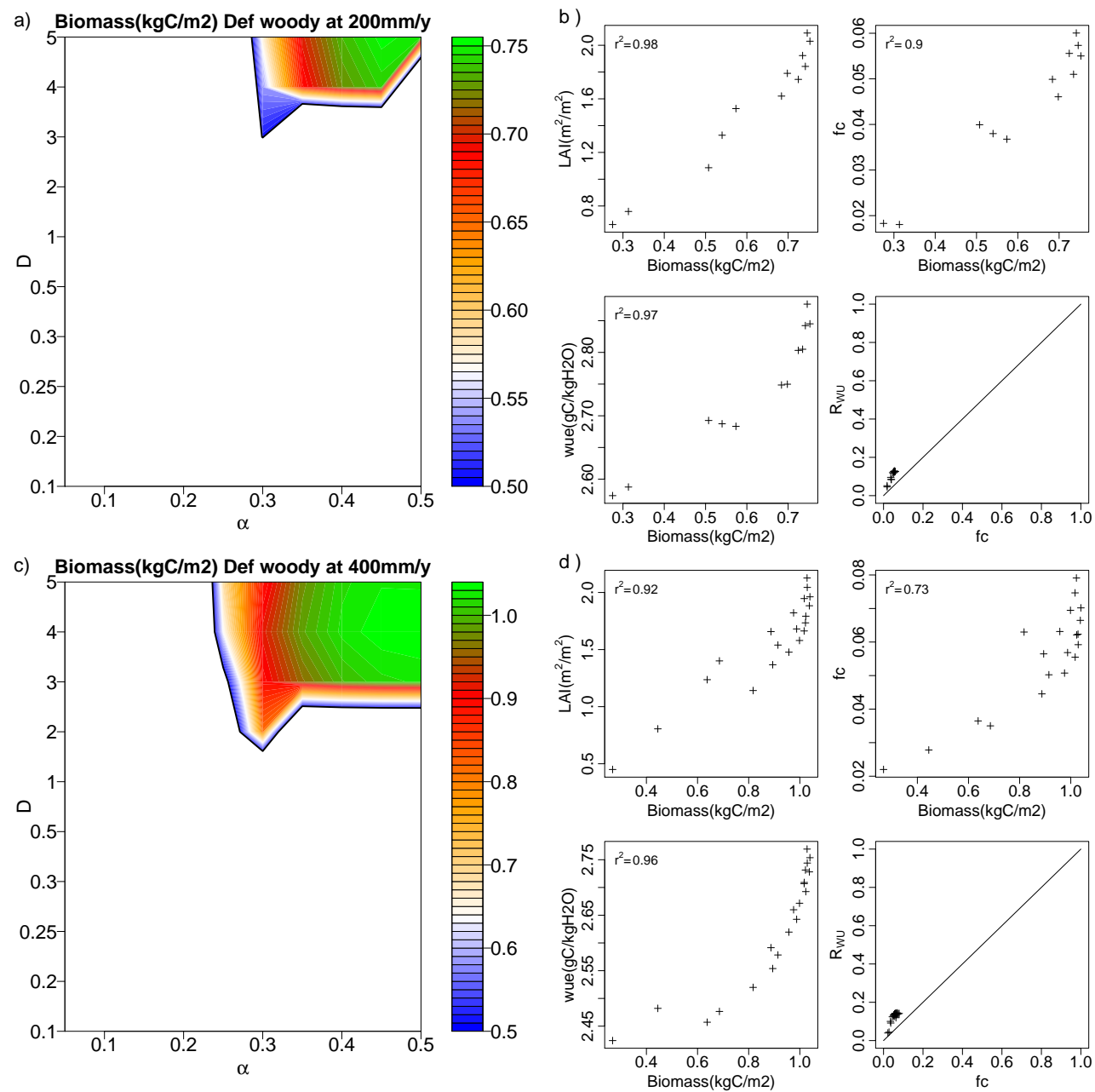

Fig. 8. Sensitivity analysis of equilibrium biomass to vegetation structure: B. As Fig. 7, defensive woody vegetation at $200 \mathrm{~mm} \mathrm{yr}^{-1}$ (panels a and $\mathbf{b}$ ) and $400 \mathrm{~mm} \mathrm{yr}^{-1}$ (c and d).

WUE is the dominant factor explaining maximum biomass variability (with the highest correlation with $C_{\mathrm{veg}}$ ). However, some structures also can generate a high WUE with low total biomass. These structures can be found when $\alpha=0.45$ and $D \approx 0.1$, where WUE is high but the total amount of water uptake (due to low LAI) is relatively low.

In contrast to the defensive case, the $f_{\mathrm{c}}$ of the optimized offensive grasses $\left(f_{\mathrm{c}}=0.5\right)$ is higher than $R_{\mathrm{WU}}$. It implies that bare soil even "borrows" water from vegetated areas. Compared to the defensive case, less water can be used by the optimized offensive grasses per vegetated area. However, the $f_{\mathrm{c}}$ of the optimized offensive grasses is much higher than that of the optimized defensive grasses. Nevertheless, the optimized defensive grasses have higher biomass per vegetated area $\left(C_{\mathrm{veg}} / f_{\mathrm{c}}\right)$; the optimized offensive grasses produce more total amount of biomass due to high $f_{\mathrm{c}}$.

\subsubsection{Wood biomass dynamics under different precipitation regimes}

Figures 8 and 9 show total biomass for woody plants with a defensive drought stress strategy for different climate regimes.

For the $200 \mathrm{~mm} \mathrm{yr}^{-1}$ precipitation regime, it is clearly illustrated that woody biomass has a smaller survival variable space than grasses. Biomass below $0.4 \mathrm{~kg} \mathrm{C} \mathrm{m}^{-2}$ cannot survive due to a minimum GPP needed for maintenance respiration. The highest biomass is found when $\alpha=0.45$ and $D=5$. In contrast to defensive grasses, the optimal defensive woody structure has a higher biomass due to longer litter timescales and thus slower biomass loss rates.

High correlation coefficients of $C_{\text {veg }}$-WUE and $C_{\text {veg }}$-LAI (Figure $8 b$ ) indicate that WUE and LAI are the primary control variables to optimize biomass. Although the correlation of $C_{\mathrm{veg}}-f_{\mathrm{c}}$ is high $\left(r^{2}=0.9\right), f_{\mathrm{c}}$ is just passively maximized with an increase of $C_{\text {veg }}$, which is not the dominant factor 

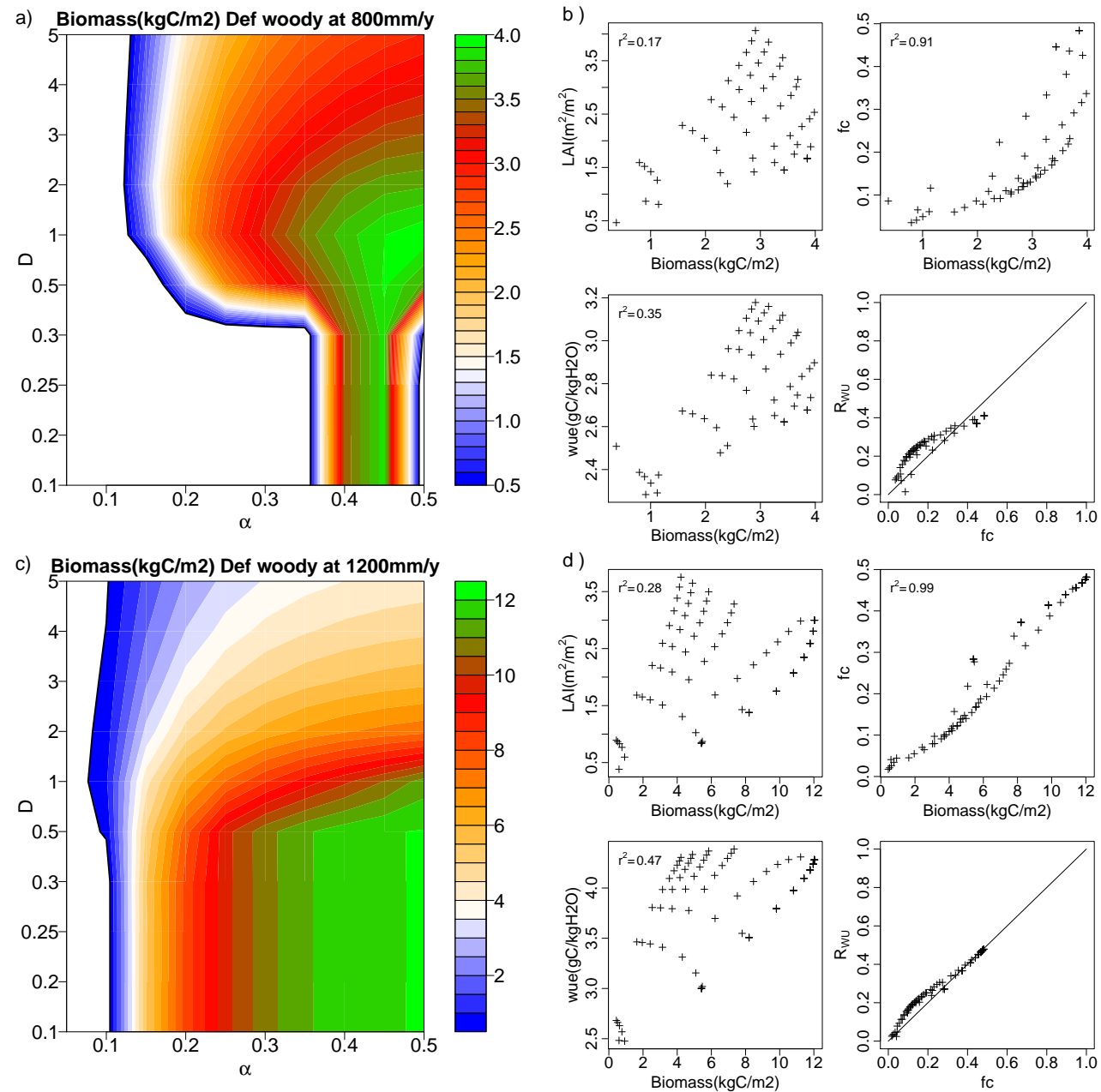

Fig. 9. Sensitivity analysis of equilibrium biomass to vegetation structure: C. As Fig. 8 for $800 \mathrm{~mm} \mathrm{yr}^{-1}$ (panels a and b) and $1200 \mathrm{~mm} \mathrm{yr}^{-1}$ (c and $\mathbf{d})$.

(also see discussion of positive and negative mechanisms in the vegetation-soil water feedback below). As before, it is of interest that the $R_{\mathrm{WU}}$ exceeds the vegetation cover. Also, woody vegetation adjusts its environment by using the water from the surrounding bare soil. For both grasses and woody vegetation types, a vertical structure is more beneficial to survive under the dry $200 \mathrm{~mm} \mathrm{yr}^{-1}$ regime. Although WUE is the dominant factor explaining total biomass variability, only optimizing WUE is not able to produce high biomass. Water uptake ability and potential photosynthesis rate are also important.

Figure $8 \mathrm{c}$ shows the biomass dependence on vegetation structure for the $400 \mathrm{~mm} \mathrm{yr}^{-1}$ precipitation regime. In this wetter regime still many combinations of $D$ and $\alpha$ lead to a vegetation structure that cannot survive. Figure $8 \mathrm{c}$ illustrates that maximum biomass is found at maximum $D$ and $\alpha$. In the wetter regime, the optimal $\alpha$ is higher and $D$ is lower than that in the $200 \mathrm{~mm} \mathrm{yr}^{-1}$ regime. Also here $R_{\mathrm{WU}}>f_{\mathrm{c}}$.
Figure 9a shows the results for the $800 \mathrm{~mm} \mathrm{yr}^{-1}$ precipitation regime. In this wetter regime, some horizontal structures start to survive. With low $D(0.1<D<0.3)$, CA almost reaches $\mathrm{CA}_{\text {ref }}$, where $f_{\mathrm{c}}$ is strongly regulated by LAI (Eq. 9). Here $\alpha$ affects the total biomass drastically. When $\alpha<0.35$, aboveground biomass is too low to gain enough carbon for maintaining root biomass. While if $\alpha>0.45$, implying lower $\varphi$, water uptake ability is not able to meet the demand for transpiration. The optimal structure is found for $\alpha=0.5$ and $D=1$. In comparison to the drier regimes shown in Fig. 8, the optimal $D$ decreases. In addition, $C_{\text {veg }}$ and $f_{\mathrm{c}}$ are highly correlated $\left(r^{2}=0.91\right)$. While at low biomass, $R_{\mathrm{WU}}$ is higher than $f_{\mathrm{c}}$. However, $f_{\mathrm{c}}$ is nearly equal to $R_{\mathrm{WU}}$ at higher biomass. We conclude that vertical vegetation uses more water from surrounding bare soil and has higher WUE, but its growth is limited by stem biomass. With a horizontal structure, the bare soil fraction is low due to a high $f_{\mathrm{c}}$. Per unit surface area vegetation shares less water from the bare soil area, but this leads to a higher biomass value with high $R_{\mathrm{WU}}$. 
Vertical structure is beneficial to survive, especially in waterlimited areas, while it is not able to produce the maximum biomass in wetter regimes. In addition, total biomass is less sensitive to WUE. Instead, leaf coverage becomes the primary factor for optimized biomass.

In the wettest regime (Fig. 9c) most combinations of $\alpha$ and $D$ can survive. Plants with low $\alpha$ cannot survive, as too much carbon is used to maintain the rooting system. Vegetation with a horizontal structure can survive, and lead to higher biomass. $f_{\mathrm{c}}$ and $R_{\mathrm{WU}}$ are almost identical (Fig. 9d), implying that water competition between bare and vegetated soil is less important. In this regime, water availability is no constraint and vegetation can survive without using water from the surrounding bare soil. Instead, high leaf coverage can avoid water loss from bare soil evaporation and increase transpiration. Biomass shows a high correlation with $f_{\mathrm{c}}$, implying the importance of $f_{\mathrm{c}}$ to optimize total biomass.

\subsection{Dominant factors for different climate regimes}

From Sects. 3.1 and 3.2, we found that LAI, $f_{\mathrm{c}}$ and WUE influence biomass significantly but their importance is climate dependent. To depict the variability of the response mechanisms as a function of the climate regime, we calculate Spearman's correlation coefficients between averaged biomass and LAI, $f_{\mathrm{c}}$ and WUE under each given climate regime for each vegetation strategy. For each grid cell in the research region (dashed rectangle in Fig. 5) and for each vegetation strategy, we simulate biomass of 100 vegetation structures as defined in Sect. 3.2. Thus we have 100 samples of simulated average biomass, LAI, $f_{\mathrm{c}}$ and WUE, which are used to calculate correlation coefficients. Cases where biomass did not survive are not taken into account. Figure 10 presents the variability of the correlation coefficients as a function of mean annual precipitation for four vegetation cases.

From Fig. 10, we can conclude that WUE and LAI are dominant factors in the low precipitation regimes between 200 and $600 \mathrm{~mm} \mathrm{yr}^{-1}$, as they generate the highest correlation to biomass. LAI generally behaves similarly to WUE. This implies that vegetation requires both a high WUE and a high potential carbon assimilation rate to survive under arid and semi-arid regimes. For low precipitation, vegetation maximizes its biomass by adopting a vertical structure, limiting $f_{\mathrm{c}}$. With the increase of precipitation, LAI and WUE are less correlated to biomass, while the correlation of $C_{\text {veg }}$ and $f_{\mathrm{c}}$ increases (Fig. 10).

\subsection{Validation}

Our results are validated against observed woody cover data (Hansen et al., 2003; Sankaran et al., 2005). In situ measurements of woody cover (Sankaran et al., 2005) are collected from several sites across Africa. The MODIS woody cover product (Hansen et al., 2003) provides a yearly satelliteretrieved tree fraction based on a regression tree algorithm.

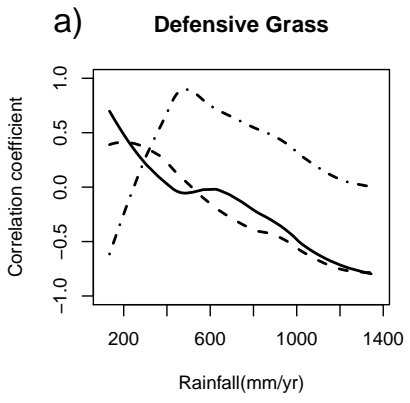

b) Offensive Grass
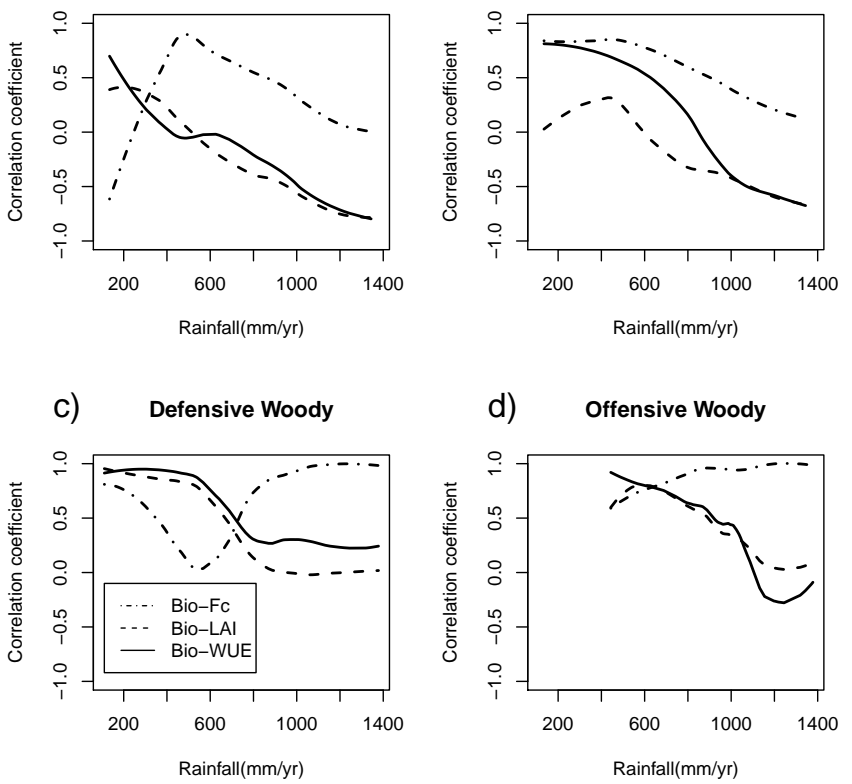

Fig. 10. Dominant factor change with precipitation. Correlation coefficients between averaged biomass and three parameters as a function of mean annual precipitation. Panels (a), (b), (c) and (d) represent defensive grass, offensive grass, defensive woody and offensive woody, respectively. Dot-dashed, dashed and solid lines are for correlation between biomass and $f_{\mathrm{c}}$, LAI and WUE, respectively.

Here we use a subsample of the MODIS woody cover data developed by Hirota et al. (2011) for validation. We assumed a shoot-total biomass ratio $\alpha=0.4$, as woody plants with $\alpha=0.4$ can more easily survive with horizontal structures (Fig. 9a). Then we chose 10 vegetation canopy structures ( $D$ varies from 0.2 to 10 ) and simulated the equilibrium tree cover in the research region (rectangle in Fig. 5).

Figure 11 illustrates the simulated and observed woody cover as a function of mean annual precipitation (MAP). Black and grey solid circles are observed tree cover data from Sankaran et al. (2005) and Hirota et al. (2011), respectively. Other colored symbols are simulated equilibrium woody cover values with different vegetation canopy structures for the research area. The maximum simulated and observed woody cover increases with MAP. The minimum MAP for tree survival, which is found from both observed and simulated results, is around $100 \mathrm{~mm} \mathrm{yr}^{-1}$. However, data from Sankaran et al. (2005) illustrate that the maximum woody cover increases until $\mathrm{MAP}=700 \mathrm{~mm} \mathrm{yr}^{-1}$, while both our results and data from Hirota et al. (2011) show that the increasing trend lasts until MAP $=900 \mathrm{~mm} \mathrm{yr}^{-1}$. When MAP $>1000 \mathrm{~mm} \mathrm{yr}^{-1}$ the maximum woody cover from simulation maintains at 0.9 , which is overestimated ( 0.8 from observations). 


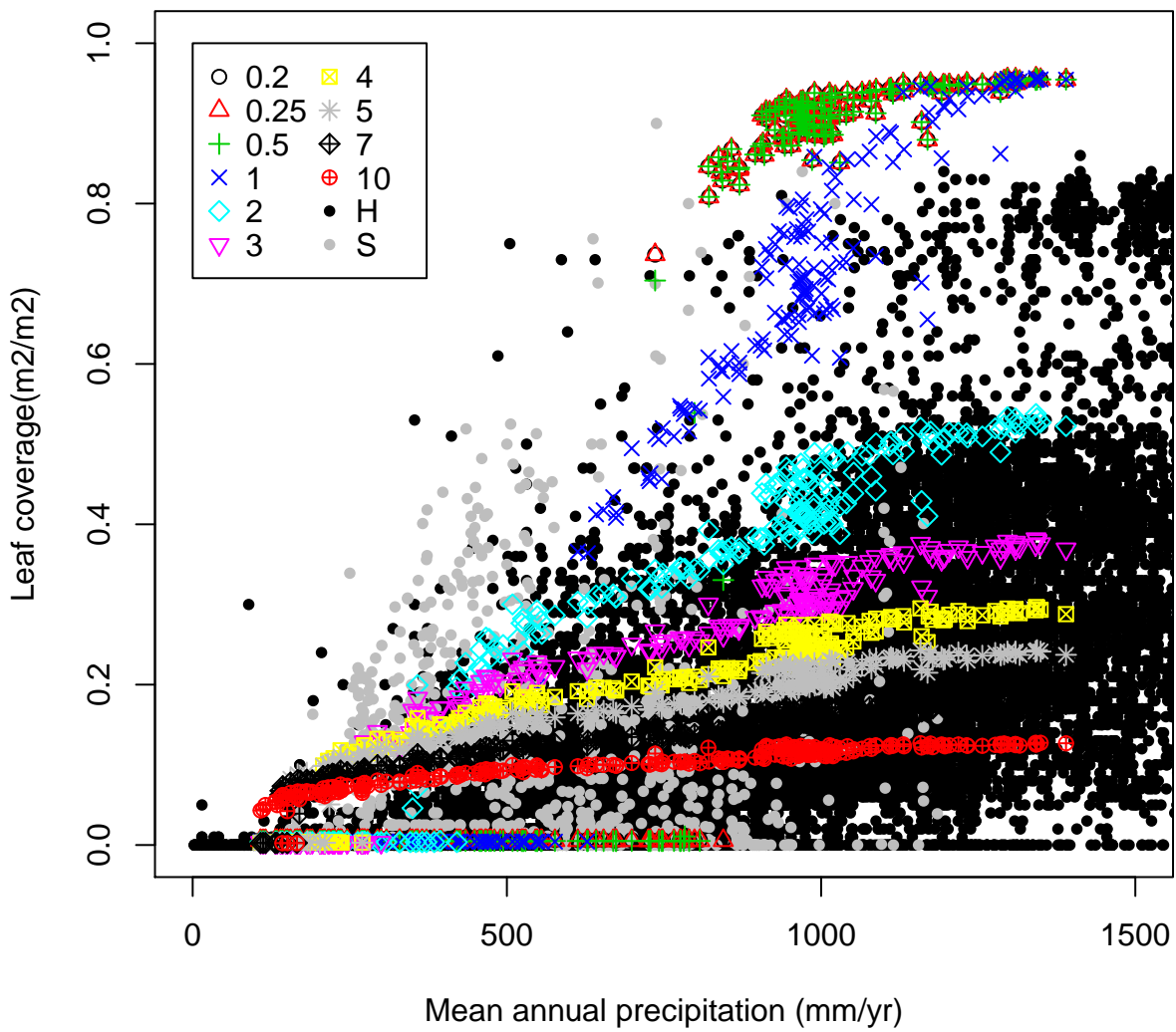

Fig. 11. Simulated and observed woody cover as a function of mean annual precipitation. Black and grey solid circles are observed tree fraction from Sankaran et al. (2005) and Hirota et al. (2011), respectively. Other symbols indicate simulated equilibrium woody cover with specific canopy structure in the study region (rectangle in Fig. 5). Related $D$ values are shown in the legend. The shoot-total biomass ratio $\alpha$ is fixed as 0.4 .

Effects of vegetation structure on simulated equilibrium woody cover are clearly shown in Fig. 11. Vertical structure (high $D$ values) easily survives under arid climate. With an increase of MAP, the equilibrium woody cover of vertical trees grows very slow. In contrast, trees with a horizontal structure hardly survive when MAP is low. However, once MAP is sufficient for their survival, they can produce a higher equilibrium cover than vertical trees.

\section{Discussion}

In this study we have developed a new model (BOSVM) to investigate the effect of vegetation spatial structure on surface carbon-water-energy cycles. The parameterization of the BOSVM model is based on several existing models (van den Hurk et al., 2000; Calvet, 2000; Cox, 2001; Sitch et al., 2003; Calvet et al., 2004; Oleson et al., 2004; ECMWF, 2008; Balsamo et al., 2009; Boussetta et al., 2013). Meanwhile, the BOSVM balances the complexity of climate, physiology, ecology and hydrology models for further vegetation-land-atmosphere interactions research.
Based on the simulation results of the BOSVM, we present findings for two questions. One is how vegetation adjusts to climate by engineering carbon allocation. The second is how the optimal vegetation structure shifts with climate regimes. For the first question, the sensitivity of biomass to vegetation structure is analyzed under a certain climate (Sect. 3.2). The shoot-total biomass ratio and canopy structure affect biomass significantly. In arid and semi-arid areas, vegetation can benefit from growing in patches (high $\mathrm{LAI} / f_{\mathrm{c}}$ ) due to the water competition between bare soil and plants. In the meantime, vegetation should carefully allocate biomass to root and leaves in order to keep a balance between water uptake ability (related to $\varphi$ ) and light absorption (related to LAI). While under wetter climate, where water is sufficient, horizontal canopy structure is preferable, which can avoid water use from evaporation. In addition, strategies of vegetation to drought has significant impact on vegetation structure.

To address the second question, we present Spearman correlation coefficients of $C_{\mathrm{veg}}-f_{\mathrm{c}}, C_{\mathrm{veg}}-\mathrm{LAI}$ and $C_{\mathrm{veg}}-\mathrm{WUE}$ as a function of mean annual precipitation (Sect. 3.3). LAI and WUE have a high correlation to $C_{\text {veg }}$ when rainfall is less than $600 \mathrm{~mm} \mathrm{yr}^{-1}$, which implies the importance of WUE and LAI to total biomass. While $f_{\mathrm{c}}$ has higher correlation 
with $C_{\text {veg }}$ when rainfall exceeds $600 \mathrm{~mm} \mathrm{yr}^{-1}$. Simultaneously, two mechanisms in the vegetation-soil water feedback are found to interpret the correlation change with precipitation.

\subsection{Optimization approach}

The objective function of vegetation optimization process follows earlier work by Schymanski et al. (2010). Compared to work of Schymanski et al. (2010), we analyze the effect of spatial structure of vegetation on water, carbon and energy balances. In addition, the BOSVM model is run by real climate forcing data. In the work of Schymanski et al. (2010), a precipitation threshold at $240 \mathrm{~mm} \mathrm{yr}^{-1}$ was found for homogeneous vegetation existence. While in our study, the threshold of homogeneous (equivalent to $\mathrm{CA}=\mathrm{CA}_{\text {ref }}$ ) grass is found at $450 \mathrm{~mm} \mathrm{yr}^{-1}$ (not shown), which coincides with the peak of grass fraction observed in Africa (Guan et al., 2012). In addition, the canopy closure of woody plants appears when precipitation is larger than $630 \mathrm{~mm} \mathrm{yr}^{-1}$, which is slightly lower than observations by Sankaran et al. (2005).

The BOSVM is validated by observed woody cover data sets from Sankaran et al. (2005) and Hirota et al. (2011). Results (Fig. 11) show that the BOSVM successfully predicted the threshold of MAP $\left(100 \mathrm{~mm} \mathrm{yr}^{-1}\right)$ for trees survival. Our results also showed that maximum woody cover increases with the increase of MAP until $1000 \mathrm{~mm} \mathrm{yr}^{-1}$, which is consistent with Hirota's data set. Moreover, by considering the variety of vegetation structure, the BOSVM is able to reproduce the large variance of observed woody cover under wet climate.

Moreover, our results show that the optimization approach (maximizing the total biomass) successfully explains why patchy vegetation is optimal under arid and semi-arid conditions (Figs. 7-9), which was also found by Schymanski et al. (2010). In contrast to a homogeneous distribution (horizontal structure), vegetation patches (vertical structure) have higher water use efficiency, which is important to biomass production under water-limited conditions.

\subsection{Two mechanisms in the vegetation-soil water feedback}

Two mechanisms in the feedback between $f_{\mathrm{c}}$ and water used by vegetation coexist. A negative mechanism concerns the infiltrated water of the bare soil part (we call it the $f_{\mathrm{c}}-R_{\text {space }}$ mechanism, see Eq. 26), while a positive mechanism addresses water loss by soil evaporation (we call it the $f_{\mathrm{c}}-R_{\mathrm{WU}}$ mechanism).

In arid and semi-arid areas, precipitation during the short monsoon season infiltrates fast into deep soil layers, which limits bare soil evaporation. Water stored in deeper layers originating from bare ground fractions of the grid box can be used for evapotranspiration by vegetation patches, leading to higher annual mean $l E_{\mathrm{v}}$ than $l E_{\mathrm{b}}$. This mechanism implies that the equilibrium biomass of vegetation patches depends on water available from both the vegetated and the bare ground fractions. A negative perturbation of the biomass decreases leads to a decrease of $f_{\mathrm{c}}$ and an increase of the bare soil area. This leads to more water per unit plant area, which will lead to a recovery of biomass. For positive perturbations of equilibrium biomass and $f_{\mathrm{c}}$, the water that vegetation can extract from the surrounding bare soil decreases. The amount of water per unit plant area is limited, by which the vegetation cannot maintain its current biomass, which will result in a decrease of biomass and $f_{\mathrm{c}}$. This $f_{\mathrm{c}}-R_{\text {space }}$ mechanism makes the vegetation fraction very resilient to climate (Holmgren and Scheffer, 2001), and thus biomass becomes more sensitive to LAI and WUE. We call this regime a "survival" state.

A $f_{\mathrm{c}}-R_{\mathrm{WU}}$ mechanism results from the notion that vegetation avoids water loss from evaporation by increasing $f_{\mathrm{c}}$. Increasing $f_{\mathrm{c}}$ leads to enhanced water availability, which accelerates $f_{\mathrm{c}}$ growth until canopy closure. Using a two-soil layer model, Baudena and Provenzale (2008) found similar vegetation feedback mechanism due to shading, which also has a beneficial effect on vegetation. This positive feedback is more noticeable under constant rainfall than under intermittent rainfall, which implies that the temporal distribution of precipitation strongly influences the impact of shading feedback to biomass. For dry climates, the relative precipitation variation is larger than that under wetter climate conditions. The importance of shading feedback to biomass rises with an increase of precipitation.

Under wetter climate conditions, with longer monsoon seasons, annual mean soil evaporation will be larger. When annual mean $l E_{\mathrm{b}}$ exceeds $l E_{\mathrm{v}}$, vegetation can use more water by increasing $f_{\mathrm{c}}$ to avoid water loss from bare soil evaporation. When biomass and $f_{\mathrm{c}}$ increase, water will not be lost by soil evaporation from the newly vegetated area. Simultaneously, as the amount of water saved exceeds the amount needed to maintain the biomass (because $\left.l E_{\mathrm{b}}>l E_{\mathrm{v}}\right)$, biomass growth will be further enhanced, leading to a near canopy closure due to the $f_{\mathrm{c}}-R_{\mathrm{WU}}$ mechanism. For woody vegetation, this $f_{\mathrm{c}}-R_{\mathrm{WU}}$ mechanism cannot lead to full coverage. From Eq. (9), we see that $f_{\mathrm{c}}$ can be increased by increasing crown area or by increasing LAI. The cost of increasing $f_{\mathrm{c}}$ is less than the increase of LAI, as no extra $C_{\text {stem }}$ is needed. This regime we call the "growing" state.

Both mechanisms exist across the gradient of precipitation in West Africa. However, the $f_{\mathrm{c}}-R_{\text {space }}$ mechanism is dominant in arid and semi-arid areas. It implies that water loss from evaporation is negligible due to the short duration of monsoon season and the fast infiltration rate. In Baudena and Provenzale (2008), under intermittent rainfall (represents the rainfall in arid and semi-arid areas), the infiltration feedback (equivalent to the $f_{\mathrm{c}}-R_{\text {space }}$ mechanism in the BOSVM model) sharply decreases the threshold of precipitation to vegetation survival. It also implies the importance of the $f_{\mathrm{c}}-$ $R_{\text {space }}$ mechanism to vegetation in dry climate. 
The $f_{\mathrm{c}}-R_{\mathrm{WU}}$ mechanism dominates when soil evaporation is too high to be ignored. The critical threshold of the dominant mechanism shifts at the point where water gain by increasing $f_{\mathrm{c}}$ is equal to the cost of biomass to support $f_{\mathrm{c}}$ increase. This threshold can be simply evaluated by comparing $l E_{\mathrm{v}}$ and $l E_{\mathrm{b}}$. When $l E_{\mathrm{v}}>l E_{\mathrm{b}}$, water loss from evaporation is worth saving. Otherwise vegetation gets more benefit by keeping in patches. Notice that the threshold is not fixed, it depends on PFT and soil types (due to infiltration rate). The threshold between the "survival" and "growing" state is determined by whether an increase in $f_{\mathrm{c}}$ is beneficial to vegetation growth (equal to whether $l E_{\mathrm{v}}>l E_{\mathrm{b}}$ or not).

In addition, the shift of dominant factors (shown in Sect. 3.3) also indicates the shift of the dominant mechanism. The threshold of dominant factor shifting is found around $600 \mathrm{~mm} \mathrm{yr}^{-1}$, where the canopy closure threshold also appears (Sankaran et al., 2005).

As our interest is modeling the effect of vegetation structure on their total biomass with a given climate regime, numerous factors that may significantly influence biomass dynamics are not taken into account. Dardel et al. (2014) found that soil type is an important driver of vegetation-climate interactions. The property of soil determines soil water-holding capacity, which in turn affects the soil water balance. Grasstree competition may limit the potential maximum biomass of grasses and woody plants. Grasses prohibit the colonization rate of woody plants and provide fuel for fire occurrence (Staver et al., 2011), which further limits the biomass of woody plants. Moreover, human activities (Kleidon, 2006) and topography (Klausmeier, 1999) have potential effects on dynamics of the ecosystem under certain climate regime, which are not considered in this work. Understanding the importance of climate regimes versus different heterogeneities of local conditions and other important mechanisms in savanna ecosystems will be an interesting and important new step.

\section{Conclusions}

This work shows how vegetation structure affects total biomass with different climate. The newly developed carbon-water-energy balances model (BOSVM) focuses on the effect of vegetation structure on photosynthesis and transpiration ability via detailed physical mechanism and runs by using realistic climate forcing data. Instead of an empirical multiplicative Jarvis model for surface conductance, we use the CHTESSEL model to calculate the surface conductance explicitly from a vegetation photosynthesis module, including its response to temperature, radiation, $\mathrm{CO}_{2}$ and water stress. By using CHTESSEL, coupling the BOSVM model to an operational version of, for instance, the ECMWF atmospheric model is made straightforward. The BOSVM model will be used in the future to investigate the role of vegetation in land-atmosphere interactions. In addition, we also introduce two vegetation structure parameters in order to explore the effect of spatial structure on vegetation biomass for different climate regimes.

An optimization approach to maximize total biomass is applied to investigate how vegetation adapts to local climate via optimizing spatial structure, which can explain why patches are optimal under arid and semi-arid conditions. We found that the optimal vegetation structure shifts with climate. Vertical canopy with medium shoot-total biomass ratio is easy to survive in arid climate, but cannot produce high biomass and coverage in wetter climate. Horizontal canopy with high shoot-total biomass ratio is hard to survive in arid climate, while it can produce high biomass and coverage in wetter climate. Two mechanisms in the vegetation-soil water feedback are found in this study. The $f_{\mathrm{c}}-R_{\text {space }}$ mechanism dominates in arid and semi-arid climate, which makes vertical canopy optimal. When the $f_{\mathrm{c}}-R_{\text {space }}$ mechanism dominates, $f_{\mathrm{c}}$ is very stable and biomass is mainly influenced by LAI and $f_{\mathrm{c}}$. The $f_{\mathrm{c}}-R_{\mathrm{WU}}$ mechanism dominates in wetter climate where the horizontal canopy is the optimal structure. When the $f_{\mathrm{c}}-R_{\mathrm{WU}}$ mechanism dominates, biomass is more sensitive to $f_{\mathrm{c}}$ than LAI and WUE. In addition, different photosynthesis strategies to drought also can influence the optimal structure. The threshold to which the dominant mechanism shifts depends on climate, but it is significantly influenced by PFTs and soil types, which may cause bi-stability under similar climate.

The BOSVM is validated by observed woody cover data sets. Results showed that the BOSVM successfully predicted the threshold of MAP $\left(100 \mathrm{~mm} \mathrm{yr}^{-1}\right)$ for trees' survival. Our results also showed that maximum woody cover increases with the increase of MAP until $1000 \mathrm{~mm} \mathrm{yr}^{-1}$, which is consistent with observed data. Moreover, by considering the variety of vegetation structure, the BOSVM model is able to interpret the large variance of observed woody cover under wet climate. 


\section{Appendix A}

\section{Vegetation response to soil water content}

In this section, we introduce two strategies that vegetation adapts to water stress. This work is explicitly described in Calvet (2000) and Calvet et al. (2004). From observations, Calvet (2000) and Calvet et al. (2004) found that soil water stress strongly influences mesophyll conductance $\left(g_{\mathrm{m}}\right)$, maximum water vaper deficit $\left(D_{\max }\right)$ and stomatal opening (represented by $f_{0}$ ). The mechanism is PFT dependent.

\section{A1 Defensive strategy for grass}

In the grass case, extractable soil water content influences $g_{\mathrm{m}}$ and $D_{\max }$ significantly. $g_{\mathrm{m}}$ determines the potential photosynthesis rate, while $D_{\max }$ has an effect on stomatal opening, which determines transpiration rate (Sect. B). There is a negative relation between $g_{\mathrm{m}}$ and $D_{\max }$ when $f_{\mathrm{w}}$ is larger than $f_{\mathrm{wc}}$ :

$\ln \left(g_{\mathrm{m}}\right)=a_{1}-b_{1} \ln \left(D_{\max }\right)$,

where $a_{1}=5.323$ and $b_{1}=0.8929 . g_{\mathrm{m}}$ is affected by $f_{\mathrm{wc}}$ and can be calculated as

$$
\begin{aligned}
g_{\mathrm{m}}= & g_{\mathrm{m}}^{X}+\left(g_{\mathrm{m}}^{*}-g_{\mathrm{m}}^{X}\right) \frac{f_{\mathrm{w}}-f_{\mathrm{wc}}}{1-f_{\mathrm{wc}}}, f_{\mathrm{w}} \geq f_{\mathrm{wc}} \\
& g_{\mathrm{m}}^{X} \frac{f_{\mathrm{w}}}{f_{\mathrm{wc}}}, f_{\mathrm{w}}<f_{\mathrm{wc}},
\end{aligned}
$$

where $g_{\mathrm{m}}^{X}\left[\mathrm{~mm} \mathrm{~s}^{-1}\right]$ corresponds to $D_{\max }^{N}$ following Eq. (A1); $g_{\mathrm{m}}^{N}\left[\mathrm{~mm} \mathrm{~s}^{-1}\right]$ corresponds to $D_{\max }^{X}$ following Eq. (A1); $f_{\mathrm{wc}}$ is the threshold of drought depending on vegetation type and strategies (Table 1); $g_{\mathrm{m}}^{*}\left[\mathrm{~mm} \mathrm{~s}^{-1}\right]$ is unstressed mesophyll conductance. $D_{\max }^{X}\left[\mathrm{~g} \mathrm{~kg}^{-1}\right]$ and $D_{\max }^{N}\left[\mathrm{~g} \mathrm{~kg}^{-1}\right]$ are maximum and minimum values of $D_{\max }$, respectively (Table 1 ).

During drought $\left(f_{\mathrm{w}}>f_{\mathrm{wc}}\right), D_{\max }$ decreases quickly, while $g_{\mathrm{m}}$ increases. When $f_{\mathrm{w}}$ falls below $f_{\mathrm{wc}}, D_{\max }$ becomes constant (stomata almost totally closed) and $g_{\mathrm{m}}$ starts to drop until photosynthesis stops. In Appendix A, $g_{\mathrm{m}}$ and $D_{\max }$ are calculated under $25^{\circ} \mathrm{C}$.

If $f_{\mathrm{w}} \geq f_{\mathrm{wc}}, D_{\max }$ is retrieved from Eq. (A1) by $g_{\mathrm{m}}$; if $f_{\mathrm{w}}<f_{\mathrm{wc}}, D_{\max }$ is equal to $D_{\max }^{N}$ as a constant.

\section{A2 Offensive strategy for grass}

In the offensive strategy of grass, the relation between $g_{\mathrm{m}}$ and $D_{\max }$ still follows Eq. (A1). However, with $f_{\mathrm{w}}$ decreasing $\left(f_{\mathrm{w}}>f_{\mathrm{wc}}\right)$ it goes to the opposite direction, which rises $D_{\max }$ to open stomata and reduce photosynthesis rate by decreasing $g_{\mathrm{m}}$. After $f_{\mathrm{w}}<f_{\mathrm{wc}}$, offensive grass starts to close stomata ( $D_{\max }$ decreases) and keep a low $g_{\mathrm{m}}$, implying an increase in WUE. $D_{\max }$ for offensive grass can be calculated by

$D_{\max }=D_{\max }^{X}+\left(D_{\text {max }}^{*}-D_{\max }^{X}\right) \frac{f_{\mathrm{w}}-f_{\mathrm{wc}}}{1-f_{\mathrm{wc}}}, f_{\mathrm{w}} \geq f_{\mathrm{wc}}$

$$
D_{\max }^{X} \frac{f_{\mathrm{w}}}{f_{\mathrm{wc}}}, f_{\mathrm{w}}<f_{\mathrm{wc}}
$$

$D_{\max }^{*}$ is calculated with unstressed $g_{\mathrm{m}}^{*}$ by Eq. (A1).

After getting $D_{\max }, g_{\mathrm{m}}$ can be calculated based on Eq. (A1) when $f_{\mathrm{w}} \geq f_{\mathrm{wc}} ; g_{\mathrm{m}}$ keeps as $g_{\mathrm{m}}^{N}$ when $f_{\mathrm{w}}<f_{\mathrm{wc}}$.

\section{A3 Defensive strategy for woody plants}

In the woody plant case, instead of $D_{\max }, g_{\mathrm{m}}$ is highly correlated to $f_{0}$, which directly determines the opening of stomata (see Appendix B). In the unstressed condition, the relation can be described by Eq. (A4). While under water-stressed conditions, Eq. (A5) is applied.

$\ln \left(g_{\mathrm{m}}^{*}\right)=4.7-7.0 f_{0}^{*}$
$\ln \left(g_{\mathrm{m}}\right)=2.8-7.0 f_{0}$

In the defensive strategy, $g_{\mathrm{m}}$ is equal to $g_{\mathrm{m}}^{*}$ when $f_{\mathrm{w}} \geq$ $f_{\mathrm{wc}}$. It is calculated based on Eq. (A4) by $f_{0}^{*}$ from Table 1 . When $f_{\mathrm{w}}<f_{\mathrm{wc}}$,

$g_{\mathrm{m}}=g_{\mathrm{m}}^{*} \frac{f_{\mathrm{w}}}{f_{\mathrm{wc}}}$.

$f_{0}$ can be calculated as

$$
\begin{aligned}
f_{0}= & f_{0}^{N}+\left(f_{0}^{*}-f_{0}^{N}\right) \frac{f_{\mathrm{w}}-f_{\mathrm{wc}}}{1-f_{\mathrm{wc}}}, f_{\mathrm{w}} \geq f_{\mathrm{wc}} \\
& \min \left(1.0, f_{0}\left(g_{\mathrm{m}}\right)\right), f_{\mathrm{w}}<f_{\mathrm{wc}},
\end{aligned}
$$

where $f_{0}^{N}[-]$ corresponds to $g_{\mathrm{m}}^{*}$ by Eq. (A5); $f_{0}\left(g_{\mathrm{m}}\right)[-]$ is the $f_{0}$ value based on Eq. (A5) with corresponding $g_{\mathrm{m}}$.

\section{A4 Offensive strategy for woody plants}

For woody plants with offensive strategy, $g_{\mathrm{m}}^{N}\left[\mathrm{~mm} \mathrm{~s}^{-1}\right]$ is calculated from Eq. (A5) by using $f_{0}^{*}$. Then the stressed $g_{\mathrm{m}}$ is given by

$$
\begin{aligned}
g_{\mathrm{m}}= & g_{\mathrm{m}}^{N}+\left(g_{\mathrm{m}}^{*}-g_{\mathrm{m}}^{N}\right) \frac{f_{\mathrm{w}}-f_{\mathrm{wc}}}{1-f_{\mathrm{wc}}}, f_{\mathrm{w}} \geq f_{\mathrm{wc}} \\
& g_{\mathrm{m}}^{N} \frac{f_{\mathrm{w}}}{f_{\mathrm{wc}}}, f_{\mathrm{w}}<f_{\mathrm{wc}} .
\end{aligned}
$$

Finally stressed $f_{0}$ can be calculated as

$$
\begin{aligned}
f_{0}= & f_{0}^{*}, f_{\mathrm{w}} \geq f_{\mathrm{wc}} \\
& \min \left(1.0, f_{0}\left(g_{\mathrm{m}}\right)\right), f_{\mathrm{w}}<f_{\mathrm{wc}} .
\end{aligned}
$$

\section{Appendix B}

\section{A-g model}

The carbon assimilation rate is inflenced by incoming solar radiation, surface temperature, vapor pressure deficit, etc. In addition, plant activities play an important role in this process. The A-g g $_{s}$ model developed by Jacobs et al. (1996) simulates the performance of vegetation in the total process. It includes impacts from radiation, temperature, vapor pressure deficit, $\mathrm{CO}_{2}$ concentration and stomatal opening. 
Table A1. Variables appeared in Appendix.

\begin{tabular}{|c|c|c|}
\hline Symbols & Unit & Variables \\
\hline$A_{\max }$ & $\mathrm{kgC} \mathrm{m}^{-2} \mathrm{~s}^{-1}$ & maximum carbon assimilation rate \\
\hline$A_{\mathrm{m}}$ & $\mathrm{kgC} \mathrm{m}^{-2} \mathrm{~s}^{-1}$ & maximum carbon assimilation rate limited by $\mathrm{CO}_{2}$ \\
\hline$A_{\mathrm{n}}$ & $\mathrm{kgC} \mathrm{m}^{-2} \mathrm{~s}^{-1}$ & carbon assimilation rate affected by radiation \\
\hline$C_{\mathrm{H}}$ & 1 & transfer coefficients to heat \\
\hline$C_{\mathrm{M}}$ & 1 & transfer coefficients to momentum \\
\hline$C_{\mathrm{Q}}$ & 1 & transfer coefficients to humidity \\
\hline$C_{\mathrm{V}}$ & $\mathrm{J} \mathrm{m}^{-3} \mathrm{~K}^{-1}$ & thermal capacity of soil \\
\hline$c_{\mathrm{i}}$ & ppm & intercellular $\mathrm{CO}_{2}$ concentration \\
\hline$c_{p}$ & $\mathrm{~J} \mathrm{~kg}^{-1} \mathrm{~K}^{-1}$ & specific heat capacity of moist air \\
\hline$D_{\max }^{*}$ & $\mathrm{~kg} \mathrm{~kg}^{-1}$ & maximum vpD without water stress \\
\hline$f$ & 1 & coupling factor that controls opening of stomata \\
\hline$f_{0}^{N}$ & 1 & $f_{0}$ corresponding to $g_{\mathrm{m}}^{*}$ \\
\hline$\Gamma$ & ppm & compensation concentration of $\mathrm{CO}_{2}$ \\
\hline$\gamma$ & $\mathrm{m} \mathrm{s}^{-1}$ & soil hydraulic conductivity \\
\hline$g_{\mathrm{m}}^{N}$ & $\mathrm{~mm} \mathrm{~s}^{-1}$ & mesophyll conductance corresponding to $D_{\max }^{X}$ \\
\hline$g_{\mathrm{m}}^{X}$ & $\mathrm{~mm} \mathrm{~s}^{-1}$ & mesophyll conductance corresponding to $D_{\max }^{N}$ \\
\hline$g_{\mathrm{sc}}$ & $\mathrm{m} \mathrm{s}^{-1}$ & stomata conductance of $\mathrm{CO}_{2}$ \\
\hline$\hat{h}$ & $\mathrm{~m} \mathrm{~m}^{-1}$ & relative height of vegetation \\
\hline$I_{\mathrm{a}}$ & $\mathrm{W} \mathrm{m}^{-2}$ & photo active radiation at top of stomata \\
\hline$L$ & $\mathrm{~m}$ & Obukhov length \\
\hline$J_{\mathrm{M}}$ & $\mathrm{J} \mathrm{m}^{-2}$ & momentum flux \\
\hline$J_{\mathrm{q}}$ & $\mathrm{W} \mathrm{m}^{-2}$ & latent heat flux \\
\hline$J_{\mathrm{S}}$ & $\mathrm{W} \mathrm{m}^{-2}$ & sensible heat flux \\
\hline$K_{\mathrm{df}}$ & 1 & extinction coefficients of diffuse light \\
\hline$K_{\mathrm{dr}}$ & 1 & extinction coefficients of direct light \\
\hline PAR & $\mathrm{W} \mathrm{m}^{-2}$ & photo active radiation at top of canopy \\
\hline$Q_{0 \mathrm{v}}$ & $\mathrm{K}$ & virtual temperature flux in the surface layer \\
\hline$q_{*}$ & $\mathrm{~ms}^{-2}$ & humidity turbulence \\
\hline$R_{\mathrm{d}}$ & $\mathrm{kgC} \mathrm{m}^{-2} \mathrm{~s}^{-1}$ & dark respiration rate \\
\hline$s_{*}$ & $\mathrm{~ms}^{-2}$ & heat turbulence \\
\hline$U_{\mathrm{n}}$ & $\mathrm{m} \mathrm{s}^{-1}$ & horizontal wind speed \\
\hline$u_{*}$ & $\mathrm{~ms}^{-1}$ & wind speed \\
\hline vpD & $\mathrm{kg} \mathrm{kg}^{-1}$ & vapor pressure deficit \\
\hline$\epsilon^{*}$ & $\mathrm{~kg} \mathrm{~J}^{-1}$ & quantum use efficiency \\
\hline$\zeta$ & 1 & stability factor of the surface layer \\
\hline$\hat{\kappa}$ & $\mathrm{m}^{2} \mathrm{~s}^{-1}$ & thermal diffusivity of soil \\
\hline$\psi$ & $\mathrm{m}$ & pressure head \\
\hline
\end{tabular}

\section{B1 Temperature effect}

The maximum of the carbon assimilation rate $\left(A_{\max }\right)$ of plants shifts with a change in surface temperature. The surface temperature $T_{\mathrm{S}}$ discussed in this Appendix is the surface temperature of vegetation part.

$$
\begin{aligned}
& A_{\max }\left(T_{\mathrm{s}}\right)=\frac{A_{\max }\left(25^{\circ} \mathrm{C}\right) \cdot Q_{\mathrm{A}_{\mathrm{m}}}^{\left(T_{\mathrm{s}}-25\right) / 10}}{\left(1+e^{0.3\left(T_{1, \mathrm{~A}_{\mathrm{m}}}-T_{\mathrm{s}}\right)}\right)\left(1+e^{0.3\left(T_{\mathrm{s}}-T_{2, \mathrm{~A}_{\mathrm{m}}}\right)}\right)} \\
& g_{\mathrm{m}}\left(T_{S}\right)=\frac{g_{\mathrm{m}}\left(25^{\circ} \mathrm{C}\right) \cdot Q_{\mathrm{g}}^{\left(T_{\mathrm{s}}-25\right) / 10}}{\left(1+e^{0.3\left(T_{1, \mathrm{~g}}-T_{S}\right)}\right)\left(1+e^{0.3\left(T_{\mathrm{s}}-T_{2, \mathrm{~g}}\right)}\right)}
\end{aligned}
$$

$\Gamma\left(T_{\mathrm{s}}\right)=\Gamma\left(25^{\circ} \mathrm{C}\right) Q_{\Gamma}^{\left(T_{\mathrm{s}}-25\right) / 10}$,

where $A_{\max }\left(T_{\mathrm{S}}\right)\left[\mathrm{kg} \mathrm{C} \mathrm{m}^{-2} \mathrm{~s}^{-1}\right]$ is the maximum carbon assimilation rate; $g_{\mathrm{m}}\left(T_{\mathrm{S}}\right)\left[\mathrm{m} \mathrm{s}^{-1}\right]$ is the mesophyll conductance; $\Gamma\left(T_{\mathrm{s}}\right)[\mathrm{ppm}]$ is the compensation concentration; $Q_{\mathrm{A}_{\mathrm{m}}}$, $Q_{\mathrm{g}}$ and $Q_{\Gamma}$ are $Q_{10}$ values for $A_{\max }, g_{\mathrm{m}}$ and $Q_{\Gamma}$, respectively, here all of them are equal to $2 ; T_{1, \mathrm{~A}_{\mathrm{m}}}$ and $T_{2, \mathrm{~A}_{\mathrm{m}}}\left[{ }^{\circ} \mathrm{C}\right]$ are reference temperatures for $A_{\max }$ calculation; $T_{1, \mathrm{~g}}$ and $T_{2, \mathrm{~g}}$ are reference temperatures for $g_{\mathrm{m}}$ calculation. Note that values of $T_{1, \mathrm{~A}_{\mathrm{m}}}, T_{2, \mathrm{~A}_{\mathrm{m}}}, T_{1, \mathrm{~g}_{\mathrm{m}}}$ and $T_{2, \mathrm{~g}_{\mathrm{m}}}$ depends on vegetation type (Table 1).

Equation (B1) shows how $A_{\max }$ is calculated by a given reference value at $25^{\circ} \mathrm{C}$ (see Table 1). The maximum effect of mesophyll conductance change with $T_{\mathrm{S}}$ is similar to $A_{\max }$ 
Table A2. Constants used in Appendix.

\begin{tabular}{|c|c|c|c|}
\hline Symbols & Unit & Description & Value \\
\hline$a$ & - & constant used in Monin-Obukhov similarity theory & 1 \\
\hline$a_{1}$ & - & factor in relation to $g_{\mathrm{m}}\left(25^{\circ} \mathrm{C}\right)$ and $D_{\max }$ & 5.323 \\
\hline$b$ & - & constant used in Monin-Obukhov similarity theory & 0.667 \\
\hline$b_{l}$ & 1 & foliage scattering coefficient & 0.944 \\
\hline$b_{1}$ & - & factor in relation to $g_{\mathrm{m}}\left(25^{\circ} \mathrm{C}\right)$ and $D_{\max }$ & 0.8929 \\
\hline$C_{1}$ & $\mathrm{~W} \mathrm{~m} \mathrm{~m}^{-1} \mathrm{~K}^{-1}$ & thermal conductivity of soil & 0.2 \\
\hline$c$ & - & constant used in Monin-Obukhov similarity theory & 5 \\
\hline$c_{\mathrm{a}}$ & ppm & $\mathrm{CO}_{2}$ concentration in the air & 388 \\
\hline$c_{p_{\text {dry }}}$ & $\mathrm{J} \mathrm{kg}^{-1} \mathrm{~K}^{-1}$ & specific heat capacity of dry air & 1013 \\
\hline$c_{p_{\text {vap }}}$ & $\mathrm{J} \mathrm{kg}^{-1} \mathrm{~K}^{-1}$ & specific heat capacity of water vapor & 2080 \\
\hline$d$ & - & constant used in Monin-Obukhov similarity theory & 0.35 \\
\hline$e$ & 1 & ratio of molecular weight of water to dry air & 0.622 \\
\hline$G_{1}$ & 1 & leaf distribution parameter & 0.5 \\
\hline$g$ & $\mathrm{~m} \mathrm{~s}^{-2}$ & acceleration due to gravity & 9.8 \\
\hline$n$ & - & soil texture parameter & 1.28 \\
\hline$Q_{\mathrm{Am}}, Q_{\mathrm{g}}, Q_{\Gamma}$ & - & exponential factor in $Q_{10}$ curve & 2 \\
\hline$z_{\mathrm{n}}$ & $\mathrm{m}$ & height of measurement & 2 \\
\hline$z_{0 \mathrm{H}}$ & $\mathrm{m}$ & height of heat measurement & 0.02 \\
\hline$z_{0 \mathrm{M}}$ & $\mathrm{m}$ & height of wind measurement & 0.2 \\
\hline$z_{0 \mathrm{Q}}$ & $\mathrm{m}$ & height of humidity measurement & 0.02 \\
\hline$\gamma_{\text {sat }}$ & $\mathrm{ms}^{-1}$ & saturated hydraulic conductivity & $1.16 \times 10^{-6}$ \\
\hline$\delta$ & 1 & $\begin{array}{l}\text { ration of diffuse to total downward shortwave radiation at the } \\
\text { top of the layer }\end{array}$ & 0.2 \\
\hline$\iota$ & - & soil texture parameter & -2.342 \\
\hline$\kappa$ & - & Von Karman's constant & 0.41 \\
\hline$\mu_{\mathrm{s}}$ & $\circ$ & solar zenith angle & 90 \\
\hline$\xi$ & $\mathrm{m}^{-1}$ & soil texture parameter & 3.14 \\
\hline$\rho_{\mathrm{W}}$ & $\mathrm{kg} \mathrm{m}^{-3}$ & liquid water density & $10^{3}$ \\
\hline$\omega$ & 1 & scattering albedo & 0.2 \\
\hline
\end{tabular}

(Eq. B2). Compensation concentration $\left(\Gamma\left(T_{\mathrm{S}}\right)\right)$ can be calculated by Eq. (B3).

\section{$\mathrm{B2} \mathrm{CO}_{2}$ effect}

The gradient of internal and external $\mathrm{CO}_{2}$ concentration determines the carbon assimilation rate. The relation between carbon-limited assimilation rate $A_{\mathrm{m}}$ and $A_{\max }$ is shown:

$A_{\mathrm{m}}=A_{\max }\left(1-e^{-\frac{g_{\mathrm{m}}\left(c_{i}-\Gamma\right)}{A_{\max }}}\right)$

where $c_{\mathrm{i}}[\mathrm{ppm}]$ is $\mathrm{CO}_{2}$ internal concentration, which is controlled by stomatal opening. With the change of water vapor deficit vpD $[\mathrm{Pa}], c_{\mathrm{i}}$ shifts between external $\mathrm{CO}_{2}$ concentration $c_{\mathrm{a}}[\mathrm{ppm}]$ and $\Gamma$.

$c_{\mathrm{i}}=f \cdot c_{\mathrm{a}}+(1-f) \Gamma$,

where $f[-]$ is the factor that determines the opening of stomata, which is influenced by vpD as

$f=f_{0}\left(1-\frac{\mathrm{vpD}}{D_{\max }}\right)$, where $f_{0}[-]$ is based on plant types and extractable water content (see Appendix A).

\section{B3 Radiation effect}

$A_{\mathrm{m}}$ is the $\mathrm{CO}_{2}$-limited assimilation rate under maximum incoming solar radiation. The final carbon assimilation will also depend on photo active radiation $\left(I_{\mathrm{a}}\right)$, as shown:

$A_{\mathrm{n}}=\left(A_{\mathrm{m}}+R_{\mathrm{d}}\right)\left(1-e^{-\frac{\epsilon^{*} I_{\mathrm{a}}}{A_{\mathrm{m}}+R_{\mathrm{d}}}}\right)-R_{\mathrm{d}}$,

where $\epsilon^{*}\left[\mathrm{~kg} \mathrm{~J}^{-1}\right]$ is the quantum efficiency according to

$\epsilon^{*}=\epsilon_{0}^{*} \frac{c_{\mathrm{i}}-\Gamma}{c_{\mathrm{i}}+2 \Gamma}$,

where $\epsilon_{0}^{*}\left[\mathrm{~kg} \mathrm{~J}^{-1}\right]$ is the maximum quantum use efficiency. $R_{\mathrm{d}}$ is dark respiration, assumed as a ratio of $A_{\mathrm{m}}$ (Eq. B9).

$R_{\mathrm{d}}=\frac{A_{\mathrm{m}}}{9}$ 
After $A_{\mathrm{n}}$ is known, we calculate stomata conductance $g_{\text {sc }}$ by Eq. (B10).

$g_{\mathrm{sc}}=\frac{A_{\mathrm{n}}+R_{\mathrm{d}}\left(1-\frac{A_{\mathrm{n}}+R_{\mathrm{d}}}{A_{\mathrm{m}}+R_{\mathrm{d}}}\right)}{c_{\mathrm{a}}-c_{\mathrm{i}}}$

Then the stomatal conductance to water vapor $g_{\mathrm{s}}$ is

$g_{\mathrm{s}}=1.6 g_{\mathrm{sc}}$.

\section{B4 Vertical integration}

The $I_{\mathrm{a}}$ is vertically integrated within the canopy. The $A_{\mathrm{n}}$ and $g_{\mathrm{s}}$ will be calculated by an integration method to get the total assimilation rate and canopy water vapor conductance (Eqs. B12 and B13). Here we assume that leaf angles of canopies are randomly distributed and the effect of clumping is not taken into account.

$$
\begin{gathered}
A_{\mathrm{n}}=\operatorname{LAI} \int_{0}^{1} A_{\mathrm{n}}(\hat{h}) \mathrm{d} \hat{h} \\
g_{\mathrm{s}}=\operatorname{LAI} \int_{\mathrm{o}}^{1} g_{\mathrm{s}}(\hat{h}) \mathrm{d} \hat{h},
\end{gathered}
$$

where $\hat{h}[-]$ is the relative height of the plant.

The $I_{\mathrm{a}}$ on the top of relative height $\hat{h}$ is given as

$I_{\mathrm{a}}(\hat{h})=\operatorname{PAR}(1-K(\hat{h}))$,

where PAR $\left[\mathrm{W} \mathrm{m}^{-2}\right.$ ] is photo active radiation on the top of the canopy. It is equal to $48 \%$ of $R_{\text {swd }}$ (Dekker et al., 2000; Boussetta et al., 2013). $K[-]$ is the extinction function, given as

$K(\hat{h})=\delta\left(\mu_{\mathrm{s}}\right) K_{\mathrm{df}}(\hat{h})+\left(1-\delta\left(\mu_{\mathrm{s}}\right)\right) K_{\mathrm{dr}}(\hat{h})$,

where $\mu_{\mathrm{s}}\left[^{\circ}\right]$ is solar zenith angle and here we assume $\mu_{\mathrm{s}}=$ $90^{\circ} ; \delta=0.2[-]$ is the ratio of diffuse to total downward shortwave radiation at the top of the layer. $K_{\mathrm{dr}}$ and $K_{\mathrm{df}}$ are extinction coefficients of direct and diffuse light:

$K_{\mathrm{dr}}(\hat{h})=1-e^{-\frac{G_{1}}{\cos \mu_{\mathrm{s}}} b_{1} \cdot \operatorname{LAI} \cdot(1-\hat{h})}$

$K_{\mathrm{df}}(\hat{h})=1-e^{-0.8 b_{1} \cdot \mathrm{LAI} \cdot(1-\hat{h})}$

where $G_{1}=0.5$ is the leaf distribution parameter; $b_{1}$ is the foliage scattering coefficient given as

$b_{1}=1-\frac{1-\sqrt{1-\omega}}{1+\sqrt{1-\omega}}$,

where $\omega$ is the scattering albedo equal to 0.2 .

Finally, we calculate GPP and NPP from $A_{\mathrm{n}}$ and $R_{\mathrm{d}}$ as

$\mathrm{GPP}=A_{\mathrm{n}}+R_{\mathrm{d}}$

$\mathrm{NPP}=A_{\mathrm{n}}$.

\section{Appendix C}

\section{Surface energy balance}

\section{C1 Monin-Obukhov similarity theory}

The diurnal surface temperature changes very fast in arid areas, which leads to strong convection at the surface layer. A simple method that uses surface wind speed and roughness length to calculate Monin-Obukhov Similarity theory is used to describe fluxes turbulence at the surface layer (ECMWF, 2008). The surface fluxes of momentum, heat and moisture are defined as

$$
\begin{aligned}
J_{\mathrm{M}} & =\rho u_{*}^{2} \\
J_{\mathrm{s}} & =\rho u_{*} S_{*} \\
J_{\mathrm{q}} & =\rho u_{*} q_{*},
\end{aligned}
$$

where $J_{\mathrm{M}}, J_{\mathrm{s}}, J_{\mathrm{q}}$ are momentum flux, sensible heat flux (equal to $H$ ) and latent heat flux (equal to $l E$ ), respectively; $u_{*}$ is friction velocity; $s_{*}$ is heat turbulence; and $q_{*}$ is humidity turbulence.

The stability parameter $L$ is the Obukhov length, defined as

$L=-\frac{u_{*}^{3}}{\frac{\kappa g}{T_{\mathrm{a}}} Q_{0 \mathrm{v}}}$,

where $\kappa$ is the Von Karman constant; $T_{\mathrm{a}}$ is air temperature at $2 \mathrm{~m}$ high; $g$ is acceleration due to gravity; and $Q_{0 \mathrm{v}}$ is virtual temperature flux in the surface layer:

$Q_{0 \mathrm{v}}=\frac{-u_{*} s_{*}-\left(c_{p_{\mathrm{vap}}}-c_{p_{\mathrm{dry}}}\right) T_{\mathrm{a}} u_{*} q_{*}}{c_{p}}+\hat{\epsilon} T_{\mathrm{a}} u_{*} q_{*}$,

where $\hat{\epsilon}=0.6$ is a constant related with water vapor and gas constant; $c_{p_{\text {vap }}}$ and $c_{p_{\text {dry }}}$ are specific heats at constant pressure of water vapor and dry air, respectively. $c_{p}$ is specific heat capacity of moist air, given by

$c_{p}=c_{p_{\text {dry }}}+\left(c_{p_{\text {vap }}}-c_{p_{\text {dry }}}\right) \cdot \mathrm{SH}$.

The three surface fluxes are calculated by

$$
\begin{aligned}
J_{\mathrm{M}} & =\rho C_{\mathrm{M}}\left|U_{\mathrm{n}}\right|^{2} \\
J_{\mathrm{s}} & =\rho C_{\mathrm{H}}\left|U_{\mathrm{n}}\right| c_{p}\left(T_{\mathrm{a}}-T_{\mathrm{s}}\right) \\
J_{\mathrm{q}} & =\rho C_{\mathrm{Q}}\left|U_{\mathrm{n}}\right|\left(q_{\mathrm{a}}\left(T_{\mathrm{a}}\right)-q_{\mathrm{sat}}\left(T_{\mathrm{s}}\right)\right),
\end{aligned}
$$

where $\left|U_{\mathrm{n}}\right|$ is wind speed; and $C_{\mathrm{M}}, C_{\mathrm{H}}$ and $C_{\mathrm{Q}}$ are transfer coefficients to momentum, heat and humidity, respectively (Eqs. C10, C11 and C12). Compared with Eqs. (16) and (19), we can find that $C_{\mathrm{H}}\left|U_{\mathrm{n}}\right|=g_{\mathrm{a}}$ and $C_{\mathrm{Q}}\left|U_{\mathrm{n}}\right|=\frac{1}{1 / g_{\mathrm{s}}+1 / g_{\mathrm{a}}}$.

$C_{\mathrm{M}}=\frac{\kappa^{2}}{\left[\log \left(\frac{z_{\mathrm{n}}+z_{0 \mathrm{M}}}{z_{0 \mathrm{M}}}\right)-\Psi_{\mathrm{M}}\left(\frac{z_{\mathrm{n}}+z_{0 \mathrm{M}}}{L}\right)+\Psi_{\mathrm{M}}\left(\frac{z_{0 \mathrm{M}}}{L}\right)\right]^{2}}$ 
$C_{\mathrm{H}}=$

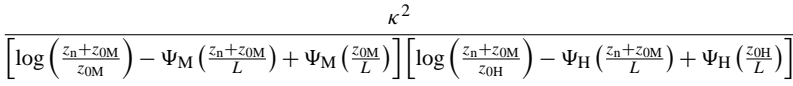

$C_{\mathrm{Q}}=$

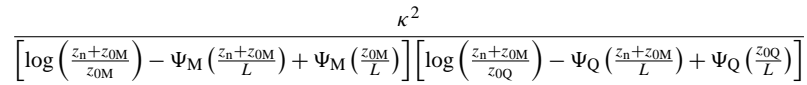

where $z_{\mathrm{n}}=2 \mathrm{~m}$ is the height of the measurement; $z_{0 \mathrm{M}}, z_{0 \mathrm{H}}$ and $z_{0 \mathrm{Q}}$ are momentum, heat and humidity roughness length, respectively.

The wind speed $\left|U_{\mathrm{n}}\right|$ is expressed as

$\left|U_{\mathrm{n}}\right|^{2}=u_{\mathrm{n}}^{2}+v_{\mathrm{n}}^{2}+w_{*}^{2}$,

where $u_{\mathrm{n}}, v_{\mathrm{n}}$ are surface wind speeds; and $w_{*}$ is the free convection velocity scale calculated as

$w_{*}=\left(z_{\mathrm{n}} \frac{g}{T_{\mathrm{a}}} Q_{0 \mathrm{v}}\right)^{1 / 3}$.

The stability functions are derived from empirical expressions. And $\zeta=\frac{z}{L}$ is used to describe the stability of the surface layer.

In unstable conditions $(\zeta<0)$, gradient functions are shown below:

$\Psi_{\mathrm{M}}(\zeta)=\frac{\pi}{2}-2 \operatorname{atan}(x)+\log \frac{(1+x)^{2}\left(1+x^{2}\right)}{8}$

$\Psi_{\mathrm{H}}(\zeta)=\Psi_{\mathrm{Q}}(\zeta)=2 \log \left(\frac{1+x^{2}}{2}\right)$

with $x=(1-16 \zeta)^{1 / 4}$.

In stable conditions $(\zeta>0)$, functions are defined as below:

$$
\begin{aligned}
& \Psi_{\mathrm{M}}(\zeta)=-b\left(\zeta-\frac{c}{d}\right) e^{-d \zeta}-a \zeta-\frac{b c}{d} \\
& \Psi_{\mathrm{H}}(\zeta)=\Psi_{\mathrm{Q}}(\zeta)=-b\left(\zeta-\frac{c}{d}\right) e^{-d \zeta}- \\
&\left(1+\frac{2}{3} a \zeta\right)^{1.5}-\frac{b c}{d}
\end{aligned}
$$

with $a=1 ; b=2 / 3 ; c=5$ and $d=0.35$.

\section{C2 Soil temperature update}

Soil heat flux is calculated by a temperature gradient from the middle of layer 1 to the surface. In this two-layer theme, we also need to update temperature change in both of the layers.

$\frac{\partial T}{\partial t}=\hat{\kappa} \frac{\partial^{2} T}{\partial z^{2}}$

$\frac{T_{1}^{i+1}-T_{1}^{i}}{\Delta t}=\hat{\kappa} \frac{\frac{2\left(T_{2}^{i}-T_{1}^{i}\right)}{z_{1}+z_{2}}-\frac{2\left(T_{1}^{i}-T_{s}^{i}\right)}{z_{1}}}{z_{1}}$

$\frac{T_{2}^{i+1}-T_{2}^{i}}{\Delta t}=\hat{\kappa} \frac{0-\frac{2\left(T_{2}^{i}-T_{1}^{i}\right)}{z_{1}+z_{2}}}{z_{1}}$, where $\hat{\kappa}=\frac{C_{1}}{C_{\mathrm{v}}}$ is thermal diffusion of soil,and $C_{\mathrm{v}}$ $\left[\mathrm{J} \mathrm{m}^{-3} \mathrm{~K}^{-1}\right]$ is soil heat capacity. $C_{\mathrm{v}}$ is given by Eq. $(\mathrm{C} 22)$.

Equation (C19) shows the diffusion of soil heat transport. Assuming that the soil heat flux from layer 2 to deeper layers is 0, we can solve Eq. (C19) by numerical methods. In Eqs. (C20) and (C21), $i$ indicates time step $i$, leading to two unknowns $\left(T_{1}^{i+1}\right.$ and $\left.T_{2}^{i+2}\right)$ in two equations.

$C_{\mathrm{v}}=2 \times 10^{6}\left(1-\theta_{\mathrm{sat}}\right)+4.2 \times 10^{6} \times \theta$,

where $\theta_{\text {sat }}\left[\mathrm{m}^{3} \mathrm{~m}^{-3}\right]$ is saturated soil moisture.

\section{Appendix D}

\section{Water balance}

In the water balance equation (Eqs. 21 and 22), Leak is the water infiltration rate from the upper to the deeper soil layer. Infiltration rate depends on soil texture and current soil moisture (Balsamo et al., 2009):

Leak $=\rho_{\mathrm{w}} \cdot \gamma$,

where $\gamma\left[\mathrm{m} \mathrm{s}^{-1}\right]$ is the hydraulic conductivity (Eq. D2), and $\rho_{\mathrm{w}}\left[\mathrm{kg} \mathrm{H}_{2} \mathrm{O} \mathrm{m}^{-3}\right]$ is liquid water density.

$\gamma=\gamma_{\mathrm{sat}} \frac{\left[\left(1+\xi \psi^{n}\right)^{1-1 / n}-\xi \psi^{n-1}\right]^{2}}{\left(1+\xi \psi^{n}\right)^{(1-1 / n)(l+2)}}$,

where $\gamma_{\text {sat }}$ is saturated hydraulic conductivity $(1.16 \times$ $\left.10^{-6} \mathrm{~m} \mathrm{~s}^{-1}\right), \xi, \iota, n$ are parameters dependent on soil texture (Table A2), $\psi$ is pressure head in meters that can be retrieved from

$\theta_{[1 ; 2]}=\theta_{\mathrm{r}}+\frac{\theta_{\mathrm{sat}}-\theta_{\mathrm{r}}}{(1+\xi \psi)^{1-1 / n}}$,

where $\theta_{\mathrm{r}}\left[\mathrm{m}^{3} \mathrm{~m}^{-3}\right]$ is the residual soil moisture, and $\theta_{\text {sat }}$ $\left[\mathrm{m}^{3} \mathrm{~m}^{-3}\right]$ is the saturated soil moisture dependent on soil texture (Table 3 ). 


\section{Code availability}

The source code of the BOSVM (v1.0) model is available as a Supplement. The later version can be obtained on request.

\section{Supplementary material related to this article is available online at http://www.geosci-model-dev.net/7/ 821/2014/gmd-7-821-2014-supplement.zip.}

Acknowledgements. We would like to thank Aaron Boone for his help on getting climatic data from the ALMIP project. We gratefully acknowledge Stan Schymanski and two anonymous referees for their useful review and comments. This research is supported by grants from Utrecht University.

Edited by: D. Lunt

\section{References}

Balsamo, G., Beljaars, A., Scipal, K., Viterbo, P., van den Hurk, B., Hirschi, M., and Betts, A.: A revised hydrology for the ECMWF model: Verification from field site to terrestrial water storage and impact in the Integrated Forecast System, J. Hydrometeorol., 10, 623-643, 2009.

Baudena, M. and Provenzale, A.: Rainfall intermittency and vegetation feedbacks in drylands, Hydrol. Earth Syst. Sci., 12, 679-689, doi:10.5194/hess-12-679-2008, 2008.

Baudena, M., D’Andrea, F., and Provenzale, A.: An idealized model for tree-grass coexistence in savannas: the role of life stage structure and fire disturbances, J. Ecol., 98, 74-80, 2010.

Bonan, G.: Forests and climate change: forcings, feedbacks, and the climate benefits of forests, Science, 320, 1444-1449, 2008.

Boone, A., Rosnay, P., Balsamo, G., Beljaars, A., Chopin, F., Decharme, B., Delire, C., Ducharne, A., Gascoin, S., Grippa, M., Jarlan, L., Kergoat, L., Mougin, E., Gusev, Y., Nasonova, O., Harris, P., Taylor, C., Norgaard, A., Sandholt, I., Ottlé, C., Poccard-Leclercq, I., Saux-Picart, S., and Xue, Y.: The AMMA land surface model Intercomparison Project (ALMIP), B. Am. Meteorol. Soc., 90, 1865-1880, 2009.

Boussetta, S., Balsamo, G., Beljaars, A., Panareda, A.-A., Calvet, J.C., Jacobs, C., Hurk, B., Viterbo, P., Lafont, S., Dutra, E., Jarlan, L., Balzarolo, M., Papale, D., and van der Werf, G.: Natural land carbon dioxide exchanges in the ECMWF Integrated Forecasting System: Implementation and offline validation, J. Geophys. Res.Atmos., 118, 5923-5946, doi:10.1002/jgrd.50488, 2013.

Calvet, J.: Investigating soil and atmospheric plant water stress using physiological and micrometeorological data, Agr. Forest Meteorol., 103, 229-247, 2000.

Calvet, J., Rivalland, V., Picon-Cochard, C., and Guehl, J.: Modelling forest transpiration and $\mathrm{CO}_{2}$ fluxes-response to soil moisture stress, Agr. Forest Meteorol., 124, 143-156, 2004.

Cox, P.: Description of the "TRIFFID" dynamic global vegetation model, Hadley Centre Technical Note, 24, 1-16, 2001.

Dardel, C., Kergoat, L., Hiernaux, P., Mougin, E., Grippa, M. and Tucker, C. J.: Re-greening Sahel: 30 years of remote sensing data and field observations (Mali, Niger), Remote Sens. Environ., 140, 350-364, 2014.

Dekker, S. C., Bouten, W., and Verstraten, J. M.: Modelling forest transpiration from different perspectives, Hydrol. Process., 14, 251-260, 2000.

Dekker, S., Rietkerk, M., and Bierkens, M.: Coupling microscale vegetation-soil water and macroscale vegetation-precipitation feedbacks in semiarid ecosystems, Global Change Biol., 13, 671-678, 2007.

Dekker, S. C., de Boer, H. J., Brovkin, V., Fraedrich, K., Wassen, M. J., and Rietkerk, M.: Biogeophysical feedbacks trigger shifts in the modelled vegetation-atmosphere system at multiple scales, Biogeosciences, 7, 1237-1245, doi:10.5194/bg-7-12372010, 2010.

Dekker, S., Vrugt, J., and Elkington, R.: Significant variation in vegetation characteristics and dynamics from ecohydrological optimality of net carbon profit, Ecohydrology, 5, 1-18, 2012.

Dewar, R.: Information theory explanation of the fluctuation theorem, maximum entropy production and self-organized criticality in non-equilibrium stationary states, J. Phys. A Math. Gen. 36, 63-641, 2003.

Dijkstra, H.: Vegetation Pattern Formation in a Semi-Arid Climate, Int. J. Bifurcat. Chaos, 21, 3497-3509, 2011.

ECMWF: IFS DOCUMENTATION CY33R1. Part IV: Physical processes, Tech. rep., ECMWF, 2008.

Entekhabi, D., Rodriguez-Iturbe, I., and Bras, R.: Variability in large-scale water balance with land surface-atmosphere interaction, J. Climate, 5, 798-813, 1992.

Guan, K., Wood, E., and Caylor, K.: Multi-sensor derivation of regional vegetation fractional cover in Africa, Remote Sens. Environ., 124, 653-665, 2012.

Hansen, M. C., DeFries, R. S., Townshend. J. R. G., Carroll, M., Dimiceli, C. and Sohlberg, R. A.: Global percent tree cover at a spatial resolution of 500 meters: First results of the MODIS vegetation continuous fields algorithm, Earth Interactions, 7, 115,2003

Higgins, S., Scheiter, S., and Sankaran, M.: The stability of African savannas: insights from the indirect estimation of the parameters of a dynamic model, Ecology, 91, 1682-1692, 2010.

Hirota, M., Holmgren, M., Van Nes, E. H., and Scheffer, M.: Global resilience of tropical forest and savanna to critical transitions, Science, 334, 232-235, 2011.

Holmgren, M. and Scheffer, M.: El Niño as a window of opportunity for the restoration of degraded arid ecosystems, Ecosystems, 4, 151-159, 2001.

Jacobs, C., van den Hurk, B., and De Bruin, H.: Stomatal behaviour and photosynthetic rate of unstressed grapevines in semi-arid conditions, Agr. Forest Meteorol., 80, 111-134, 1996.

Jarvis, P.: The interpretation of the variations in leaf water potential and stomatal conductance found in canopies in the field, Philos. Trans. Roy. Soc. London. B, 273, 593-610, 1976.

Kéfi, S., Rietkerk, M., Alados, C., Pueyo, Y., Papanastasis, V., ElAich, A., and De Ruiter, P.: Spatial vegetation patterns and imminent desertification in Mediterranean arid ecosystems, Nature, 449, 213-217, 2007.

Klausmeier, C.: Regular and irregular patterns in semiarid vegetation, Science, 284, 1826-1828, 1999. 
Kleidon, A.: Optimized stomatal conductance of vegetated land surfaces and its effects on simulated productivity and climate, Geophys. Res. Lett, 31, L21203, doi:10.1029/2004GL020769, 2004.

Kleidon, A.: The climate sensitivity to human appropriation of vegetation productivity and its thermodynamic characterization, Glob. Planet Change, 54, 109-127, 2006.

Kleidon, A. and Schymanski, S.:Thermodynamics and optimality of the water budget on land: a review, Geophys. Res. Lett, 35, L20404, doi:10.1029/2008GL035393, 2008.

Konings, A. G., Dekker, S., Rietkerk, M., and Katul, G. G.: Drought sensitivity of patterned vegetation determined by rainfall-land surface feedbacks, J. Geophys. Res.-Biogeosci., 116, G04008, doi:10.1029/2011JG001748, 2011.

Koster, R., Dirmeyer, P., Guo, Z., Bonan, G., Chan, E., Cox, P., Gordon, C., Kanae, S., Kowalczyk, E., Lawrence, D., Liu, P., Lu, C.-H., Malyshev, S., McAvaney, B., Mitchell, K., Mocko, D., Oki, T., Oleson, K., Pitman, A., Sud, Y. C., and Taylor, C. M., Verseghy, D., Vasic, R., Xue, Y., and Yamada, T.: Regions of strong coupling between soil moisture and precipitation, Science, 305, 1138-1140, 2004.

Malhi, Y., Doughty, C., and Galbraith, D.: The allocation of ecosystem net primary productivity in tropical forests, Philos. Trans. Roy. Soc. B, 366, 3225-3245, 2011.

Oleson, K., Dai, Y., Bonan, G., Bosilovich, M., Dickinson, R., Dirmeyer, P., Hoffman, F., Houser, P., Levis, S., Niu, G.-Y., Thornton, P., Vertenstein, M., Yang, Z.-L., and Zeng, X.: Technical description of the community land model (CLM), Tech. rep., NCAR Technical Note NCAR/TN-461+ STR, National Center for Atmospheric Research, Boulder, CO, 2004.

Rietkerk, M., Boerlijst, M., van Langevelde, F., HilleRisLambers, R., van de Koppel, J., Kumar, L., Prins, H., and de Roos, A.: Self-organization of vegetation in arid ecosystems, The American Naturalist, 160, 524-530, 2002.

Rietkerk, M., Brovkin, V., van Bodegom, P., Claussen, M., Dekker, S., Dijkstra, H., Goryachkin, S., Kabat, P., van Nes, E., Neutel, A., Nicholson, S. E., Nobre, C., Petoukhov, V., Provenzale, A., Scheffer, M., and Seneviratne, S. I.: Local ecosystem feedbacks and critical transitions in the climate, Ecol. Complex., 8, 223228, 2011.

Rodriguez-Iturbe, I., D'odorico, P., Porporato, A., and Ridolfi, L.: On the spatial and temporal links between vegetation, climate, and soil moisture, Water Resour. Res., 35, 3709-3722, 1999.
Sankaran, M., Hanan, N., Scholes, R., Ratnam, J., Augustine, D., Cade, B., Gignoux, J., Higgins, S., Le Roux, X., Ludwig, F., Ardo, J., Banyikwa, F., Bronn, A., Bucini, G., Caylor, K. K., Coughenour, M. B., Diouf, A., Ekaya, W., Feral, C. J., February, E. C., Frost, P. G. H., Hiernaux, P., Hrabar, H., Metzger, K. L., Prins, H. H. T., Ringrose, S., Sea, W., Tews, J., Worden, J., and Zambatis, N.: Determinants of woody cover in African savannas, Nature, 438, 846-849, 2005

Schymanski, S., Roderick, M., Sivapalan, M., Hutley, L., and Beringer, J.: A test of the optimality approach to modelling canopy properties and $\mathrm{CO}_{2}$ uptake by natural vegetation, Plant. Cell Environ., 30, 1586-1598, 2007.

Schymanski, S., Roderick, M., Sivapalan, M., Hutley, L., and Beringer, J.: A canopy-scale test of the optimal water-use hypothesis, Plant. Cell Environ., 31, 97-111, 2008.

Schymanski, S. J., Kleidon, A., Stieglitz, M., and Narula, J.: Maximum entropy production allows a simple representation of heterogeneity in semiarid ecosystems, Philos. Trans. Roy. Soc. B, 365, 1449-1455, 2010.

Seneviratne, S., Corti, T., Davin, E., Hirschi, M., Jaeger, E., Lehner, I., Orlowsky, B., and Teuling, A.: Investigating soil moistureclimate interactions in a changing climate: A review, Earth-Sci. Rev., 99, 125-161, 2010.

Sitch, S., Smith, B., Prentice, I., Arneth, A., Bondeau, A., Cramer, W., Kaplan, J., Levis, S., Lucht, W., Sykes, M., Thonicke, K., and Venevsky, S.: Evaluation of ecosystem dynamics, plant geography and terrestrial carbon cycling in the LPJ dynamic global vegetation model, Global Change Biol., 9, 161-185, 2003.

Staver, A. C., Archibald, S., and Levin, S. A.: The global extent and determinants of savanna and forest as alternative biome states, Science, 334, 230-232, 2011.

Teuling, A., Seneviratne, S., Stöckli, R., Reichstein, M., Moors, E., Ciais, P., Luyssaert, S., Van Den Hurk, B., Ammann, C., Bernhofer, C., Dellwik, E., Gianelle, D., Gielen, B., Grünwald, T., Klumpp, K., Montagnani, L., Moureaux, C., Sottocornola, M., and Wohlfahrt, G.: Contrasting response of European forest and grassland energy exchange to heatwaves, Nat. Geosci., 3, 722727, 2010.

van den Hurk, B., Viterbo, P., Beljaars, A., and Betts, A.: Offline validation of the ERA40 surface scheme, European Centre for Medium-Range Weather Forecasts, 2000.

Zeng, N., Neelin, J. D., Lau, K. M., and Tucker, C. J.: Enhancement of interdecadal climate variability in the Sahel by vegetation interaction, Science, 286, 1537-1540, 1999. 